\title{
A unique signal sequence of the chemokine receptor CCR7 promotes package into COPII vesicles for efficient receptor trafficking
}

\author{
Edith Uetz-von Allmen Alexandra V. Rippl Hesso Farhan* Daniel F. Legler
}

Biotechnology Institute Thurgau (BITg), University of Konstanz, Kreuzlingen, Switzerland

\section{Correspondence}

Daniel F. Legler, BITg, University of Konstanz, Unterseestrasse 47, CH-8280 Kreuzlingen, Switzerland. Email: daniel.legler@bitg.ch

*Present address: Institute of Basic Medical Sciences, University of Oslo, Oslo, Norway

\begin{abstract}
Chemokine receptors are considered to belong to the group of $\mathrm{G}$ protein-coupled receptors that use the first transmembrane domain as signal anchor sequence for membrane insertion instead of a cleavable $\mathrm{N}$-terminal signal sequence. Chemokine recognition is determined by the $\mathrm{N}$-termini of chemokine receptors. Here, we show that the chemokine receptor CCR7, which is essential for directed migration of adaptive immune cells, possesses a 24 amino acids long $\mathrm{N}$-terminal signal sequence that is unique among chemokine receptors. This sequence is cleaved off the mature human and mouse protein. Introducing single point mutations in the hydrophobic core h-region or in the polar $\mathrm{C}$-terminal segment (c-region) of the signal sequence to interfere with its cleavage retained CCR7 in the ER and prevented its surface expression. Furthermore, we demonstrate the correct topology of the 35 amino acids short extracellular N-tail of CCR7 in a deletion mutant lacking the natural signal sequence. This signal sequence deletion mutant of CCR7 is fully functional as it efficiently binds its ligand, elicits chemokine-induced calcium mobilization, and directs cell migration. However, we show that the signal sequence promotes efficient recruitment of the GPCR to ER exit sites, thereby controlling efficient ER to Golgi trafficking of CCR7 on its way to reach the plasma membrane.

KEYWORDS

cell migration, G protein-coupled receptor, Golgi, ligand binding, protein export
\end{abstract}

\section{1 | INTRODUCTION}

Chemokine signaling is crucial for coordinated cell migration in health and disease. ${ }^{1}$ Typically chemokines signal through chemokine receptors belonging to the $\gamma$ subfamily of rhodopsin-like (class A), G-protein coupled receptors (GPCRs) to orchestrate cell migration. ${ }^{2}$ Structurally, chemokine receptors span the plasma membrane by 7 transmembrane $\alpha$-helices that are connected by 3 extracellular and 3 intracellular loops. The extracellular $\mathrm{N}$-terminus of the receptor is linked through a disulfide bond to the third extracellular loop and considered to control chemokine binding and ligand specificity. ${ }^{3,4}$ Negatively charged amino acids of the receptor's $\mathrm{N}$-terminus are generally thought to interact first with the basic core domain of the chemokine ligand, which posi-

Abbreviations: CCR7, CC chemokine receptor 7; COPII, coat protein complex II; ERES, endoplasmic reticulum exit site; $\mathrm{ET}_{\mathrm{B}} \mathrm{R}$, endothelin $\mathrm{B}$ receptor; $\mathrm{GPCR}, \mathrm{G}$ protein-coupled receptor; RUSH, retention using selective hooks system; $\mathrm{SBP}$, streptavidin-binding peptide; ss, signal sequence; TM, transmembrane domain tions the chemokine's $\mathrm{N}$-terminus such that it facilitates its insertion into the binding pocked defined by the 7 transmembrane bundles of the receptor. ${ }^{3-5}$ Chemokine receptors are highly dynamic structures and signaling efficiency principally relies on the discrete interaction with the chemokine ligand. ${ }^{6}$

The chemokine receptor CCR7, together with its ligands CCL19 and CCL21, plays a crucial role in the guidance of the adaptive immune system. ${ }^{1,7,8}$ CCR7 not only contributes to guiding early T cell progenitors through the thymus during $T$ cell maturation, it also guides lymphoid tissue inducer cells required for the development of lymph nodes. Furthermore, CCR7 is essential in guiding antigen-bearing dendritic cells and lymphocytes into lymph nodes either from peripheral tissues via afferent lymphatics or from the blood circulation through high endothelial venules. Notably, misguidance of these leukocytes, for example, in CCR7 gene targeted mice or in plt/plt mice, a naturally occurring mouse strain lacking CCL19 and CCL21-Ser results in a defective adaptive immune response and can lead to the development 
of multi-organ autoimmune diseases. ${ }^{7}$ Moreover, if expressed by cancer cells, CCR7 contributes to their dissemination, migration, and the formation of metastasis. ${ }^{9}$

Given the importance of CCR7 and its ligands to the numerous processes, it is vital that this system is tightly regulated to ensure appropriate responses. Whereas inflammatory signals are known to induce and regulate CCR7 expression and migration in dendritic cells, ${ }^{10,11}$ posttranslational modifications of CCR7 emerge to critically regulate its activity. For instance, ubiquitylation of CCR7 has been found to control receptor trafficking and hence cell migration. ${ }^{12}$ Tyrosine sulfation in the N-terminus of CCR7 was recently identified to significantly enhance CCL21 binding. ${ }^{13}$ In addition, polysialylation of CCR7 was found to be essential for CCL21 recognition and hence dendritic cell homing to lymph nodes. ${ }^{14}$ Moreover, we identified that distinct glycosylation patterns on CCR7's N-terminus and third extracellular loop shape receptor signaling and endocytosis to control leukocyte migration by CCL19 and CCL21. ${ }^{15}$

Regulatory mechanisms underlying the complex expression and transport of multi-pass transmembrane GPCRs, and chemokine receptors in particular, to the plasma membrane are still relatively unexplored. ${ }^{16,17}$ The first step of intracellular transport of membrane proteins is the insertion into the ER membrane, which is mediated by signal sequences. Two distinct types of signal sequences are known for GPCRs. ${ }^{18}$ The majority of GPCRs use the first transmembrane domain (TM) of the mature protein as non-cleavable signal anchor sequence, which directly binds to the signal recognition particle directing the ribosome and the nascent receptor to the ER membrane. In contrast, about $5-10 \%$ of GPCRs possess $\mathrm{N}$-terminal signal sequences that are removed by signal peptidases during the translocon-mediated receptor insertion into the ER membrane. ${ }^{19}$ Protein folding, membrane insertion, and assembly then occurs co-translationally. ${ }^{20}$ Prior to the release of the complete receptor into the membrane interior, individual helices of incompletely synthesized GPCRs can be retained in the vicinity of the translocon with membrane integration of the nascent chain occurring only after several TM helices have been biosynthesized. ${ }^{21}$ This provides one additional possibility to regulate surface expression. The reason one group requires cleavable signal sequence whereas others do not is not really understood. ${ }^{19}$

Chemokine receptors are thought to belong to the group of GPCRs using TM1 as signal anchor sequence. This is supported by studies using $\mathrm{N}$-terminally epitope-tagged receptors for detection, which are not cleaved as exemplified for CCR2 ${ }^{22,23}$ and CXCR4. ${ }^{24,25}$ In 1995, by comparing the N-terminal tails of a large collection of GPCRs, EBI1 was predicted to possess a cleavable signal sequence. ${ }^{26}$ Upon identification of the chemokines CCL19 and CCL21 as ligands for EBI1, the receptor was renamed to CCR7. ${ }^{27,28}$ Although no one addressed it experimentally, it was originally speculated, but widely neglected in the chemokine field, that the putative cleaved signal sequence of EBI1/CCR7 comprising 24 amino acids was necessary for efficient posttranslational translocation of the remaining 35 amino acid short extracellular N-tail of the GPCR, which includes several positively charged residues. ${ }^{26}$ Using SignalP, a state-of-the-art predictor of the presence and location of cleavable signal sequences, ${ }^{29}$ we found that CCR7, but no other chemokine receptor, possesses a predicted cleavable signal sequence (Table 1 ). In this study, we experimentally addressed whether CCR7 indeed possesses a unique cleavable signal sequence and whether the signal sequence regulates receptor surface expression and ligand binding.

\section{MATERIALS AND METHODS}

\section{1 | Plasmid constructs}

The pcDNA3-based expression vector of human CXCR4 including an $\mathrm{N}$-terminal HA-tag (YPYDVPDYA epitope following the start codon) was a kind gift of Adriano Marchese. ${ }^{30}$ CXCR4 was replaced for human CCR7 to receive pCDNA3-HA-huCCR7 for the expression of an N-terminally HA-tagged human CCR7. ${ }^{31}$ A pcDNA3.1 construct containing an internal FLAG-tag (DYKDDDDK epitope) between the $\mathrm{N}$-terminal signal sequence and the residual sequence of the murine CCR7 receptor (pcDNA3.1-ss-FLAG-CCR7) was kindly provided by Jens Stein. An N-terminal FLAG-tag was introduced into the entire open reading frame of mouse CCR7 by PCR (fw_primer: 5' TGGAATTCATGGACTACAAGGACGACGATGACAAGGACCCAGGGA AACCCAGGAAAAACGTG, rev_primer: 5' CCTCTAGACTACGG GGAGAAGGTTGTGGTGGTC; restriction sites underlined) and cloned into the EcoRI and Xbal sites of pcDNA3 (Invitrogen, Carlsbad, CA) to generate pcDNA3-FLAG-ss-CCR7. This construct was used as a template to introduce point mutations in the signal sequence by site-directed mutagenesis using the following primers: $5^{\prime}$ CATTTTCCAGGTGTGCTTCAAACAAGATGAGGTCACCGATGAC to generate pcDNA3-FLAG-CFK-CCR7, 5' CATTTTCCAGGTGTICTTCT ICCAAGATGAGGTCACCGATGAC to obtain pcDNA3-FLAGFFF-CCR7, and 5' CGTGCTGGTGGTGGCTAACAATGTCAAA TTCCAGGTGTGCTTCTGCC for the plasmid pcDNA3-FLAGhr-CCR7 (QuickChange Site-Directed Mutagenesis Kit, Agilent, Santa Clara, CA). All FLAG-tags were replaced by an HA-tag by PCR cloning fw_primer: 5' TATAGAATTCATGTA CCCATACGATGTTCCAGATTACGCTGACCCAGGGAAACCCAGGA; rev_primer: 5' TTAATCTAGACTACGGGGAGAAGGTTGTGGTGGTCT CC) to generate pcDNA3-HA-ss-CCR7 and its mutants. PCR amplifications were performed using the Expand High FidelityPLUS PCR system (Roche; Sigma-Aldrich). The construct pcDNA3.1-ss-HACCR7 was cloned by overlap extension PCR FastCloning method ${ }^{32}$ using Phusion High-Fidelity DNA Polymerase (Thermo\#F531) and primers 5' ATACGATGTTCCAGATTACGCTCAAGATGAGGT CACCGATGAC and ATCTGGAACATCGTATGGGTAGCAGAAGCA CACCTGGAAAATGA on pCDNA3.1-ss-FLAG-CCR7 as template to replace its FLAG-tag with an HA-tag. To clone pcDNA3- $\Delta$ ssHA-CCR7, a fragment of 1095 nucleotides was amplified by PCR on pcDNA3.1-ss-Flag-CCR7 as template using a forward primer to introduce the methionine followed by the HA-tag and the first 19 coding nucleotides of mature mouse CCR7 (fw_primer: 5' TATAGAATTCATGTACCCATACGATGTTCCAGATTACGCTCAAGATGA GGTCACCGATG, rev_primer: 5' TTAATCTAGACTACGGGGAGAAGG TTGTGGTGGTCTCC) and subsequently inserted into pcDNA3 
TAB LE $1 \mathrm{~N}$-termini and predicted signal sequences of human and mouse chemokine receptors

\begin{tabular}{|c|c|c|}
\hline \multicolumn{3}{|l|}{ A } \\
\hline Receptor & (Human) Predicted N-terminal amino acid sequence ${ }^{a}$ & {$[\%]^{b}$} \\
\hline CCR1 & METPNTTEDYDTTTEFDYGDATPCQKVNERAFGA & 0.0 \\
\hline CCR2 & MLSTSRSRFIRNTNESGEEVTTFFDYDYGAPCHKFDVKQIGA & 0.0 \\
\hline CCR3 & MTTSLDTVETFGTTSYYDDVGLLCEKADTRALMA & 0.0 \\
\hline CCR4 & MNPTDIADTTLDESIYSNYYLYESIPKPCTKEGIKAFGE & 0.0 \\
\hline CCR5 & MDYQVSSPIYDINYYTSEPCQKINVKQIAA & 0.0 \\
\hline CCR6 & MSGESMNFSDVFDSSEDYFVSVNTSYYSVDSEMLLCSLQEVRQFSRL & 0.0 \\
\hline CCR7 & MDLGKPMKSVLVVALLVIFQVCLCQDEVTDDYIGDNTTVDYTLFESLCSKKDVRNFKAW & 98.3 \\
\hline CCR8 & MDYTLDLSVTTVTDYYYPDIFSSPCDAELIQTNGK & 0.0 \\
\hline CCR9 & MADDYGSESTSSMEDYVNFNFTDFYCEKNNVRQFASH & 0.0 \\
\hline CCR10 & MGTEATEQVSWGHYSGDEEDAYSAEPLPELCYKADVQAFSRAFQPSVSLTVA & 0.0 \\
\hline CXCR1 & MSNITDPQMWDFDDLNFTGMPPADEDYSPCMLETETLNK & 0.0 \\
\hline CXCR2 & MEDFNMESDSFEDFWKGEDLSNYSYSSTLPPFLLDAAPCEPESLEINK & 0.0 \\
\hline CXCR3 & MVLEVSDHQVLNDAEVAALLENFSSSYDYGENESDSCCTSPPCPQDFSLNFDR & 0.0 \\
\hline CXCR4 & MEGISIYTSDNYTEEMGSGDYDSMKEPCFREENANFNKI & 0.0 \\
\hline CXCR5 & MNYPLTLEMDLENLEDLFWELDRLDNYNDTSLVENHLCPATEGPLMASFKAVFVP & 0.0 \\
\hline CXCR6 & MAEHDYHEDYGFSSFNDSSQEEHQDFLQFSKV & 0.0 \\
\hline XCR1 & MESSGNPESTTFFYYDLQSQPCENQAWVFAT & 0.0 \\
\hline CX3CR1 & MDQFPESVTENFEYDDLAEACYIGDIVVFGT & 0.0 \\
\hline \multicolumn{3}{|l|}{ B } \\
\hline Receptor & (Mouse) Predicted N-terminal amino acid sequence ${ }^{a}$ & {$[\%]^{b}$} \\
\hline CCR1 & MEISDFTEAYPTTTEFDYGDSTPCQKTAVRAFGA & 0.0 \\
\hline CCR2 & MEDNNMLPQFIHGILSTSHSLFTRSIQELDEGATTPYDYDDGEPCHKTSVKQIGA & 0.1 \\
\hline CCR3 & MAFNTDEIKTVVESFETTPYEYEWAPPCEKVRIKELGS & 0.0 \\
\hline CCR4 & MNATEVTDTTQDETVYNSYYFYESMPKPCTKEGIKAFGE & 0.0 \\
\hline CCR5 & MDFQGSVPTYSYDIDYGMSAPCQKINVKQIAA & 0.0 \\
\hline CCR6 & MNSTESYFGTDDYDNTEYYSIPPDHGPCSLEEVRNFTKV & 0.0 \\
\hline CCR7 & MDPGKPRKNVLVVALLVIFQVCFCQDEVTDDYIGENTTVDYTLYESVCFKKDVRNFKAW & 95.9 \\
\hline CCR8 & MDYTMEPNVTMTDYYPDFFTAPCDAEFLLRGSM & 0.0 \\
\hline CCR9 & MMPTELTSLIPGMFDDFSYDSTASTDDYMNLNFSSFFCKKNNVRQFASH & 0.1 \\
\hline CCR10 & MGTKPTEQVSWGLYSGYDEEAYSVGPLPELCYKADVQAFSRAFQPSVS & 0.0 \\
\hline CXCR1 & MAEAEYFIWTNPEGDFEKEFGNITGMLPTGDYFIPCKRVPITNR & 0.0 \\
\hline CXCR2 & MGEFKVDKFNIEDFFSGDLDIFNYSSGMPSILPDAVPCHSENLEINS & 0.0 \\
\hline CXCR3 & MYLEVSERQVLDASDFAFLLENSTSPYDYGENESDFSDSPPCPQDFSLNFDR & 0.0 \\
\hline CXCR4 & MEPISVSIYTSDNYSEEVGSGDYDSNKEPCFRDENVHFNRI & 0.0 \\
\hline CXCR5 & MNYPLTLDMGSITYNMDDLYKELAFYSNSTEIPLQDSNFCSTVEGPLLTSFKAVFMP & 0.0 \\
\hline CXCR6 & MDDGHQESALYDGHYEGDFWLFNNSSDNSQENKRFLKFKEV & 0.0 \\
\hline XCR1 & MDSESDALSIPASRVQMESSTAFYDYHDKLSLLCENNVIFFST & 0.0 \\
\hline CX3CR1 & MSTSFPELDLENFEYDDSAEACYLGDIVAFGT & 0.0 \\
\hline
\end{tabular}

aPredicted N-terminus by UniProt (http://www.uniprot.org/uniprot/).

b Maximal signal sequence cleavage site probability [in percent] determined by SignalP 3.0 (http://www.cbs.dtu.dk/services/SignalP-3.0/).

Predicted signal sequence in CCR7 is underlined and bold.

using the restriction sites EcoRI and Xbal. To obtain the plasmid pEGFP-HA-ss-CCR7-GFP for the expression of N-terminally HA-tagged mouse CCR7 and C-terminally fused to eGFP, the sequence coding for HA-ss-CCR7 was amplified by PCR (fw_primer; 5' TATAGAATTCATGTACCCATACGATGTTCCAGATTACGCTGACCC, rev_primer: 5' TTAAGGTACCAACGGGGAGAAGGTTGTGGTGGTCT
CCGC) and cloned into the EcoRI and Kpnl restriction sites of plasmid pEGFP-N1 from Clontech (Takara Bio USA, Inc.). The mutant receptor variants pEGFP-HA-CFK-CCR7-GFP, pEGFPHA-FFF-CCR7-GFP, and pEGFP-HA-hr-CCR7-GFP were cloned accordingly. The following forward primers were used for cloning of pEGFP-ss-HA-CCR7-GFP (fw_primer: 5' TATAGAATTCATGG 
ACCCAGGGAAACCCAGGAAAAAC) and (fw_primer: 5' TATAGAATTCATGTACCCATACGATGTTCCAGATTACGCTCAAGATG) for pEGFP- $\triangle$ ss-HA-CCR7-GFP, respectively. For transient transfection studies of GFP constructs, the CMV promotor was replaced by the human proximal CCR7 promoter region amplified by PCR from genomic DNA using recognition primers that contained sites for BgIII at the $5^{\prime}$ end and HindIII at the $3^{\prime}$ end to include a fragment of nucleotides -574 to -1 from the first base coding for the methionine of exon 1 (fw_primer: 5' ATATAGATCTGGAGGGGAGGGGAAGGGGGGAGAAAAAA, rev primer: 5' TATAAAGCTTGACGCTCTCTGGGCGGTAAAACC), and subcloned into the pGL3 reporter vector from the Promega Corporation (Madison, WI). This plasmid was then used as template for PCR amplification of the same promoter element introducing Asel and Bglll sites (fw_primer: 5' - TTAAATTAATGGAGGGGA GGGGAAGGGGGGAGAAAAAAG, rev_primer: 5' - TATAAGATCTGAC GCTCTCTGGGCGGTAAAACC) which was then inserted into the pEGFP-based CCR7 expression vectors.

ER-hooked (cytosolic li hook), murine wildtype (ss-CCR7-RUSHGFP), or mutant CCR7 lacking the signal peptide ( $\Delta$ ss-CCR7-RUSHGFP) expression constructs were generated by replacing VSVG in the cloning cassette 1 of the VSVGwt-SBP-EGFP plasmid (provided by Franck Perez) with the sequence coding for CCR7 excluding its stop codon or any unrelated signal sequence using the Ascl and EcoRI sites. The following primers were used for PCR amplification of CCR7 on pcDNA3-HA-ss-CCR7 as template: fw_ss-CCR7-RUSH-GFP; 5' TATAGGCGCGCCATGGACCCAGGGAAACCCAGGAAAAAC, fw_ $\triangle$ ssCCR7-RUSH-GFP; 5' TATAGGCGCGCCATGCAAGATGAGGTCACCG ATGACTACATC, rev_primer; 5' TTAAGAATTCAGCGGGGAGAAG GTTGTGGTGGTC. Orientation and sequences of all the constructs were confirmed by sequencing (Microsynth, Balgach, Switzerland). The plasmid mOrange2-Golgi-7 $7^{33}$ was purchased from Addgene (Cambridge, MA).

\subsection{Cell lines and transfection}

HeLa and HEK293 cells were cultured in DMEM (V.W.R.) supplemented with 10\% FCS (Linaris; Dossenheim, Germany) and 1\% Pen/Strep (BioWhittaker Lonza; VWR Scientific, Nyon, Switzerland). Transfections were performed with liposomal reagents (TransIT-LT, Mirus Bio LLC, Madison, WI) according to the manufacturer's instructions. To establish cell lines or clones stably expressing $\mathrm{N}$-terminally HA-tagged human CCR7 or CXCR4, HEK293 cells were grown under a selective pressure of $1 \mathrm{mg} / \mathrm{ml} \mathrm{G} 418$ until no further cell death was observed. The selected cells were stained with an antibody specific for human CCR7 or CXCR4 and sorted on a BD FACSVantage SE cell sorter (BD Biosciences, Erembodegem, Belgium) to obtain single positive clones. HEK293 cells stably expressing C-terminally GFP-tagged CCR7 were grown in the presence of $0.5 \mathrm{mg} / \mathrm{ml} \mathrm{G} 418$ and single cell sorting for high GFP-expression was performed on a BD FACSAria II cell sorter (BD Biosciences). Cells sorted for medium to high surface expression of CCR7 on the FACSAria II cell sorter were grown under a selective pressure of $0.8 \mathrm{mg} / \mathrm{ml} \mathrm{G} 418$.
Murine 300-19 pre-B cells were grown in RPMI1640 with UltraGlutamine supplemented with 10\% FCS, $50 \mu \mathrm{M} \beta$-mercaptoethanol (Gibco; LuBioScience, Luzern, Switzerland), 1\% v/v Pen/Strep, and $1 \%$ nonessential amino acids (Lonza). A total of $1 \times 10^{6} 300-19$ cells were transfected with the Amaxa Cell Line Nucleofector Kit V (Lonza) and grown for 2 weeks in the presence of $0.8 \mathrm{mg} / \mathrm{ml} \mathrm{G} 418$. Bulk cell sorting for medium to high CCR7 surface expression using an antibody reacting with mouse CCR7 was performed on a BD FACSAria II cell sorter (BD Biosciences).

\section{3 | Flow cytometry}

Transfected HEK293 cells were detached with Trypsin-Versene (V.W.R.), washed once with PBS and stained for 20 min at $4^{\circ} \mathrm{C}$ with antibody in staining buffer (PBS, $0.5 \% \mathrm{FCS}$, or $0.05 \mathrm{M}$ Tris buffered saline ( $\mathrm{pH}$ 7.4), containing $1 \mathrm{mM} \mathrm{CaCl}{ }_{2}$ for anti-FLAG M1 stainings). Unbound antibody was removed by 2 washing steps with staining buffer, and SYTOX Blue (Invitrogen; LuBio) was added as a dead cell indicator. All samples were filtered $(50 \mu \mathrm{M}$ Cup Filcons; BD Biosciences), measured with a LSRII flow cytometer using the FACSDiva 6 software (BD Biosciences), and analyzed with the FlowJo software (Tree Star, Inc.; Ashland, OR). The following antibodies or conjugates were used: Biotin or Alexa Fluor 488 labeled HA.11 Clone 16B12 monoclonal antibody obtained from Covance (Lucerna-Chem AG; Luzern, Switzerland), anti-HA-FITC, unlabeled anti-FLAG M1 and anti-FLAG $\mathbb{R}$ M2-FITC (Sigma-Aldrich; Buchs, Switzerland), anti-human CCR7-APC, anti-human CXCR4-APC, and isotype controls (R\&D Systems; Minneapolis, MN), PE-labeled polyclonal antibody specific for the Fc fragment of heavy chains on human IgG, Streptavidin-APC, PE- or APClabeled anti-mouse CCR7 (clone 4B12), and isotype controls from eBioscience (Affymetrix; Frankfurt, Germany), sheep anti-mouse Ig $\mathrm{F}\left(\mathrm{ab} \mathrm{b}^{\prime}\right)_{2}$ fragment FITC-conjugated secondary antibody (Chemicon; Melbourne, Australia). Monoclonal anti-mouse CD16/CD32 antibody (Fc block) was used prior to staining of mouse CCR7 on the surface of 300-19 cells.

\section{4 | CCL19-Fc binding}

HEK293 cell lines stably expressing ss-HA-CCR7 or Dss-HA-CCR7 were detached, washed twice, and then incubated with graded concentrations of CCL19-Fc (produced in HEK293 cells ${ }^{31}$ ) for 30 min on ice in PBS, $0.5 \%$ FCS (FACS buffer). Cells were washed twice at $4^{\circ} \mathrm{C}$ with ice-cold FACS buffer and then stained for another 20 min on ice with a PE-labeled secondary antibody. For flow cytometry analysis, cells were washed twice, resuspended in FACS buffer, and analyzed on a LSRII Flow Cytometer. CCR7 surface expression was determined in parallel after staining with APC-labeled rat anti-mouse CCR7 or rat lgG2a isotype control.

\section{5 | Migration assay}

300-19 cells stably expressing mouse ss-HA-CCR7 or $\triangle$ ss-HA-CCR7 $\left(1 \times 10^{5}, 100 \mu \mathrm{l}\right)$ were seeded in the top chambers with $5-\mu \mathrm{m}$ pore size of the Transwells (Corning Costar; Vitaris). Lower chamber wells contained $500 \mu \mathrm{l}$ of medium supplied without chemokine (random 
migration) or with increasing concentrations of human CCL19 or CCL21 (PeproTech; LuBio). Cells were allowed to migrate for $3.5 \mathrm{~h}$ at $37^{\circ} \mathrm{C}, 5 \% \mathrm{CO}_{2}$. Filters were removed and cells in the lower chamber were collected and acquired for $90 \mathrm{~s}$ at high flow rate on a LSRII flow cytometer. Percent specific migration was calculated by dividing the number of the cells migrated to the lower well by the total cell input (100 $\mu \mathrm{l}$ cell suspension directly added to $500 \mu \mathrm{l}$ medium without chemokine in the lower chamber) multiplied by 100 and subtracting random migration (always less than $0.04 \%$ ) to the lower chamber without chemokine present. Parental 300-19 cells were used as negative control. Flow cytometry analysis was performed in parallel to confirm similar levels of CCR7 surface expression by the transfectants.

\section{6 $\mid \mathrm{Ca}^{2+}$ flux assay}

300-19 cells stably expressing mouse ss-HA-CCR7 or $\triangle$ ss-HA-CCR7 were washed with loading-buffer $(145 \mathrm{mM} \mathrm{NaCl}, 5 \mathrm{mM} \mathrm{KCl}, 1 \mathrm{mM}$ $\mathrm{Na}_{2} \mathrm{HPO}_{4}, 1 \mathrm{mM} \mathrm{MgCl}$, $5 \mathrm{mM}$ glucose, $1 \mathrm{mM} \mathrm{CaCl}$, and $10 \mathrm{mM}$ HEPES $(\mathrm{pH} 7.5))$, resuspended $\left(1 \times 10^{6} / \mathrm{ml}\right)$, and labeled with $4 \mu \mathrm{M}$ Fluo-3-AM (Molecular Probes; Leiden, the Netherlands) for $20 \mathrm{~min}$ at $37^{\circ} \mathrm{C}$. Cells were washed twice with loading-buffer, and chemokineinduced calcium mobilization-related fluorescence intensity changes of the $\mathrm{Ca}^{2+}$-sensitive dye Fluo-3 were recorded over time by flow cytometry as described. ${ }^{15,31}$ Data were corrected for mean basal fluorescence intensity before stimulation and normalized to the mean intensity in the presence of ionomycin $(1 \mu \mathrm{g} / \mathrm{ml})$ to account for differences in fluorescent dye loading of each cell type.

\section{7 | Confocal microscopy}

HEK293 cells stably expressing wildtype or mutant $\mathrm{N}$-terminally HAtagged CCR7-GFP variants were grown overnight on $18 \mathrm{~mm}$ round coverslips $\left(7.5 \times 10^{4}\right.$ cells per well in a 12 -well tissue culture plate). Cells were washed with PBS and fixed with $3 \%$ Paraformaldehyde for $10 \mathrm{~min}$ at room temperature followed by permeabilization with $20 \mathrm{mM}$ glycine, $0.2 \%$ Triton $\mathrm{X}-100$ in PBS for $5 \mathrm{~min}$ at room temperature. Cells were washed 3 times with PBS and incubated with a mouse primary antibody specific for Climp63 (diluted 1/1000 in PBS, 3\% BSA) for $1 \mathrm{~h}$ at room temperature. Cells were washed again followed by staining with Alexa Fluor 568 labeled donkey anti-mouse IgG secondary antibody (Thermo Fisher Scientific; Allschwil, Switzerland; 1/1000 dilution) for $1 \mathrm{~h}$. Coverslips were washed and mounted using polyvinyl alcohol mounting medium (Fluka; Sigma-Aldrich) prior to imaging on a confocal laser scanning microscopy (Leica TCS SP5; Leica, Heerbrugg, Switzerland) using the HCX PL APO CS $63.0 \times 1.40$ OIL UV objective ( $63 \times$ magnification, numerical aperture $=1.4)$. The same confocal laser scanning device and objective were also used in RUSH immunolabeling and live-cell imaging experiments. For the comparison of digital images, ${ }^{34}$ they were acquired under identical conditions and identically processed post-acquisition. The Huygens Essential image processing software (Scientific Volume Imaging; Hilversum, the Netherlands) was used for deconvolution of stacks of microscopic images to improve image resolution.

\subsection{RUSH system}

Cells grown overnight on coverslips $\left(7.5 \times 10^{4} \mathrm{HeLa}\right.$ cells per well in a 12-well plate containing an $18 \mathrm{~mm}$ round coverslip) were transfected with $0.4 \mu \mathrm{g}$ ss-CCR7-RUSH-GFP or $\Delta$ ss-CCR7-RUSH-GFP construct for 20-24 h. To allow release of the hooked receptor from the ER, transfectants were treated with $40 \mu \mathrm{M}$ biotin (Sigma B4639) for indicated time points at $37^{\circ} \mathrm{C}$. Cells were washed with PBS, fixed with $3 \%$ PFA for 15 min at room temperature followed by permeabilization with $20 \mathrm{mM}$ glycine, $0.2 \%$ Triton X-100 in PBS for $5 \mathrm{~min}$ at room temperature. Finally, cells were washed with PBS and stained with a mouse monoclonal anti-GM130 primary antibody diluted 1/1000 in PBS, 3\% BSA for $60 \mathrm{~min}$ at room temperature. After washing and incubation with Alexa Fluor 568-conjugated secondary antibody diluted 1/1000 in PBS, 3\% BSA for $60 \mathrm{~min}$ at room temperature, coverslips were washed and mounted prior to confocal imaging (Leica TCS SP5). The acquired cell images were processed with ImageJ software from $\mathrm{NIH}$ (National Institutes of Health, USA). To quantify the kinetics/efficiency of receptor trafficking to the Golgi upon synchronic release from the ER hook, a region of interest was drawn around the Golgi area for individual cells as defined by the GM130 fluorescence signal (red). The mean CCR7-RUSH-GFP (green) fluorescence pixel intensities in the Golgi area were measured and divided by the mean background GFP fluorescence measured in a corresponding perinuclear extraGolgi region exhibiting the same size and shape. The mean Golgi association of CCR7 (Golgi/non-Golgi ratio) was calculated for 120 representative cells, excluding cells with highly fragmented Golgi and exhibiting similar mean GFP fluorescence intensities for comparison of both groups (ss-CCR7-RUSH-GFP versus $\Delta$ ss-CCR7-RUSH-GFP) per condition collected from three separate experiments.

For live-cell imaging, HeLa cells were seeded overnight at $2 \times 10^{5}$ in $2 \mathrm{ml}$ growth medium in a sterile $35 \mathrm{~mm}$ ibiTreat high wall glass $\mathrm{u}-$ dish (IBIDI; Vitaris, Baar, Switzerland). One microgram CCR7-RUSHGFP construct was transiently cotransfected with $100 \mathrm{ng}$ of the plasmid encoding photostable mOrange2-Golgi-7 for $20 \mathrm{~h}$. HEPES (20 mM) was then freshly added to the medium, and cells were equilibrated for a period of 20-30 $\mathrm{min}$ in the incubator of the Leica TCS SP5 confocal microscope at $37^{\circ} \mathrm{C}$ prior to the imaging procedure. Frames were taken before exposure to biotin and every $30 \mathrm{sec}$ for 20-30 min after the release of CCR7-RUSH-GFP from the ER by careful addition of biotin at a final concentration of $40 \mu \mathrm{M}$ on top of the medium beneath the region containing the cells to be analyzed to prevent loss of focus. The time point of concurrence of green fluorescent CCR7-RUSH-GFP in the Golgi region (orange fluorescence) upon addition of biotin was determined and data were collected from $n=8$ experiments, with 3 to 12 cells per construct analyzed per experiment, plotted as mean seconds \pm SD.

To monitor accumulation of ER-hooked $(\Delta)$ ss-CCR7-RUSH-GFP at ERESs after biotin-mediated release of the proteins from the ER, cells grown overnight on round coverslips $\left(2 \times 10^{5} \mathrm{HeLa}\right.$ cells per $2 \mathrm{~cm}$ dish) were transfected with $1 \mu \mathrm{g}$ ss-CCR7-RUSH-GFP or $\Delta$ ss-CCR7-RUSHGFP construct for $20 \mathrm{~h}$ prior to treatment with $40 \mu \mathrm{M}$ biotin (start of the longest $2 \mathrm{~h}$ incubation time point). Addition of biotin at indicated time points was preceded by an equilibration step for $30 \mathrm{~min}$ at $15^{\circ} \mathrm{C}$ to 

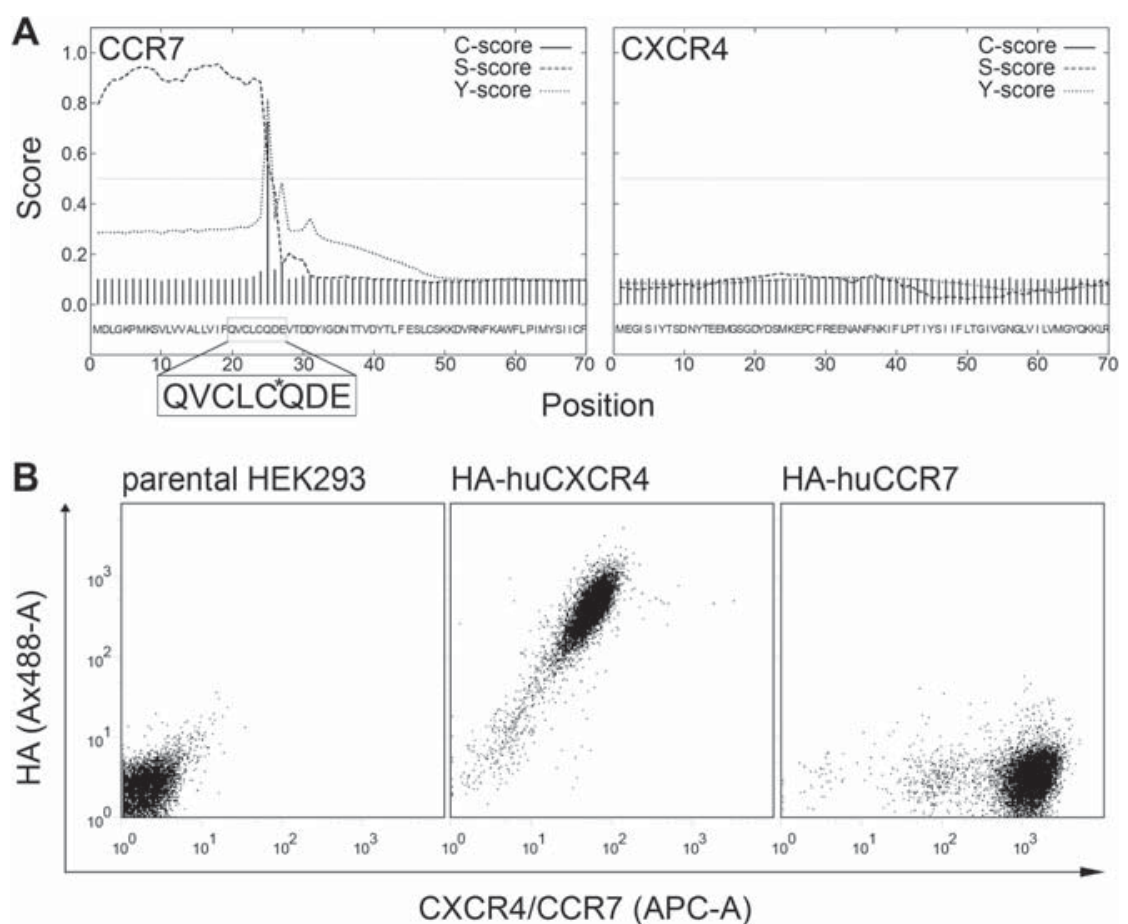

FIGURE 1 CCR7, but not CXCR4, possesses a cleavable $\mathrm{N}$-terminal signal sequence. (A) In silico analysis of the $\mathrm{N}$-termini of human CCR7 and CXCR 4 by SignalP 3.0 reveals a putative cleavable signal sequence for CCR7 (cleavage site indicated by ${ }^{*}$ ), but not CXCR4. SignalP 3.0 predicts 3 different scores for each amino acid. $A$ high $C$ and $Y$ score indicate a cleavage site, whereas amino acids of the mature protein are indicated by a low $\mathrm{S}$ score. (B) $\mathrm{N}$-terminally HAtagged human CXCR4 and CCR7 were stably expressed in HEK293 cell clones. Both receptors were expressed at the surface as determined by flow cytometry, but the $\mathrm{N}$-terminal HA-tag was detectable at the surface of CXCR4, but not CCR7, expressing cells. One representative data set from $n=3$ block ER-to-Golgi trafficking in the presence of $20 \mathrm{mM} \mathrm{HEPES} \mathrm{freshly}$ added to the medium. Cells without biotin treatment served as control. Cells were fixed in the presence of $4 \%$ ultra-pure methanol-free formaldehyde (Polysciences; Warrington, PA) directly added to the tissue culture medium for $15 \mathrm{~min}$ at $15^{\circ} \mathrm{C}$ and then washed 3 times with PBS at room temperature. Permeabilization of the cells in PBS containing $0.2 \%$ Triton X-100 for $5 \mathrm{~min}$ at room temperature was followed by washing 3 times with PBS. Cells were stained with primary mouse monoclonal antibody directed against the ERES marker Sec31A diluted $1 / 1000$ in PBS, 3\% BSA for 45 min at room temperature followed by washing and incubation with Alexa Fluor 568-conjugated secondary antibody diluted $1 / 1000$ in PBS, $3 \%$ BSA for 35 min at room temperature. Coverslips were mounted as described above and cells were imaged (Leica TCS SP5). Concurrence of CCR7-RUSH-GFP in ERES upon addition of biotin was determined per cell by counting the total number of ERES (red fluorescence) and the number of ERES containing the receptor with visible green fluorescence.

\subsection{Statistical data analysis}

Nonparametric comparisons between unpaired data sets were analyzed by a two-tailed Mann-Whitney $U$ test using GraphPad Prism 6 software. Error bars represent the SD. Box and Whiskers plots demonstrate the median and extreme values, as well as the 25 th and 75th percentiles.

\section{3 | RESULTS}

\subsection{Identification of a unique signal sequence cleavage site for human and mouse CCR7}

Chemokine receptors are considered to belong to the group of GPCRs that use the first TM as signal anchor sequence for membrane inser- tion and hence seem not to possess a cleavable $\mathrm{N}$-terminal signal sequence. Moreover, the $\mathrm{N}$-termini of chemokine receptors are generally considered as pivotal for binding their ligands. ${ }^{3}$ Before it was recognized as chemokine receptor CCR7, EBI1 has been postulated to cleave off its putative $\mathrm{N}$-terminal signal sequence from its mature protein. ${ }^{26}$ Hence, we decided to determine whether the signal sequence of CCR7 is cleaved or not. We first exploited SinalP 3.0 (http://www.cbs.dtu.dk/services/SignalP-3.0/) 29,35 to predict the presence and location of cleavable signal sequences in all classical chemokine receptors. These in silico sequence analyses of the $\mathrm{N}$ termini of human chemokine receptors revealed a cleavable signal sequence exclusively for CCR7 (UniProt ID: P32248 for human CCR7) with a $P$ value of 0.990 and a maximal cleavage site $P$ of 0.983 between residues Cys24 and Gln25 (Table 1; Fig. 1A). The N-termini of any other classical chemokine receptor, including CXCR4 (UniProt ID: P61073-1, output graph for isoform 1 shown in Fig. 1A), was predicted as non-cleavable (Table 1 ). To experimentally address signal sequence cleavage, we cloned N-terminally HA-tagged human CCR7 and CXCR4, respectively, such that the tag precedes the corresponding signal sequence, and expressed them in HEK293 cells. Both the Nterminal HA-tag and CXCR4 were readily detected simultaneously at the surface of HEK293 cell transfectants by flow cytometry using HAtag-specific and CXCR4-specific antibodies (Fig. 1B). These data confirm previous studies on $\mathrm{N}$-terminally tagged CXCR4 ${ }^{24,25}$ and clearly reveal that no parts of the $\mathrm{N}$-terminus of CXCR4 are removed. In contrast, in cells expressing N-terminally HA-tagged CCR7, only a receptor specific antibody, but not the HA-tag-specific antibody was able to detect CCR7 at the cell surface (Fig. 1B), providing first experimental evidence that CCR7 indeed possesses a signal sequence that is cleaved off the mature protein.

Correspondingly, SignalP 3.0 analysis of the $\mathrm{N}$-termini of all classical mouse chemokine receptors (Table 1B) predicted a signal sequence 

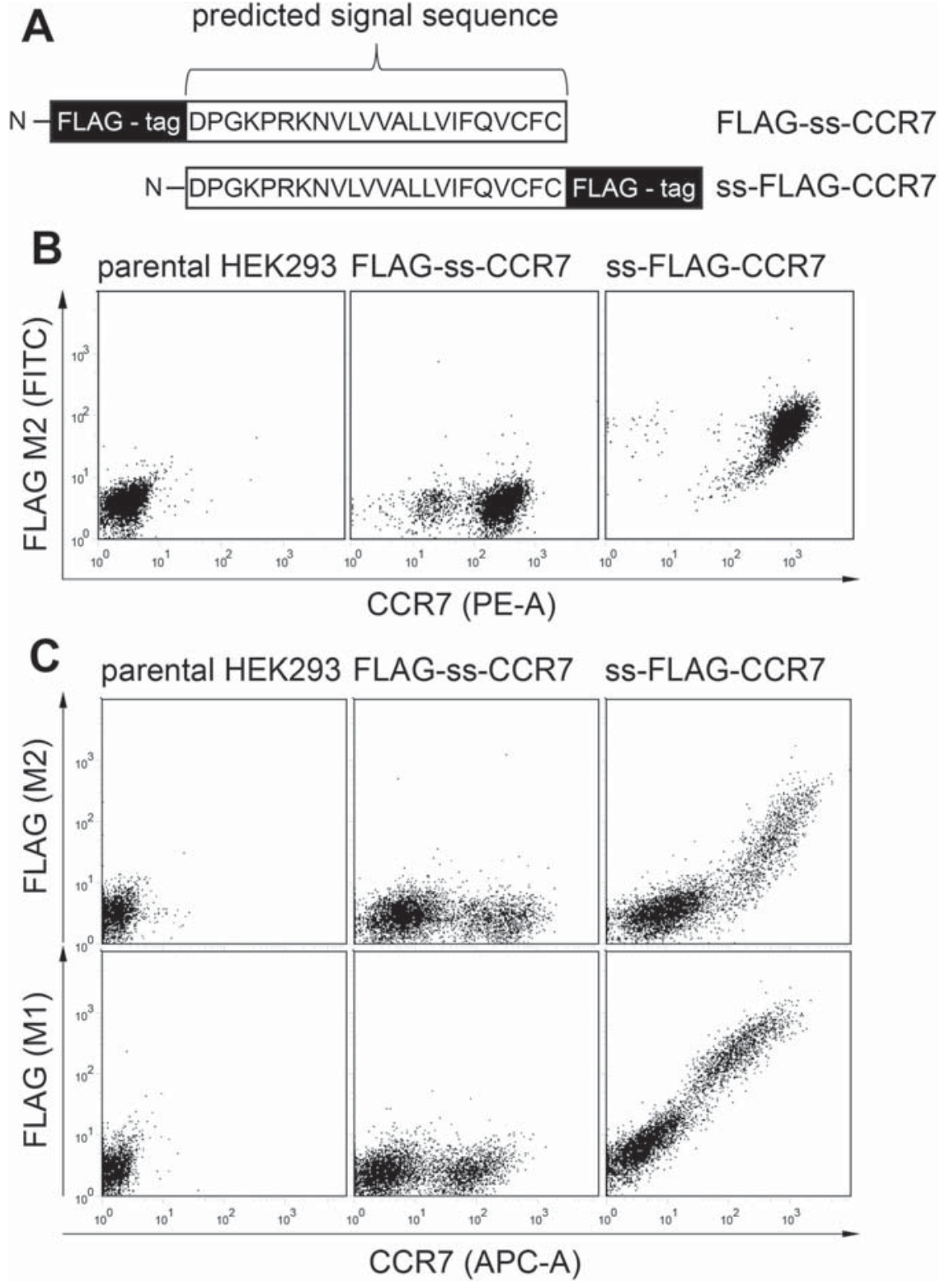

FIGURE 2 Identification of the CCR7 signal sequence cleavage site. (A) Schematic representation of the expression constructs of mouse CCR7 used to identify the signal sequence cleavage site. A FLAG-peptide epitope was introduced at the N-terminal end (FLAG-ssCCR7) or immediately after the predicted signal sequence cleavage site and in front of the putative mature protein (ss-FLAG-CCR7). (B) FACS analysis of HEK293 cell clones stably expressing FLAG-ss-CCR7 or ss-FLAG-CCR7. Surface expression of CCR7 and its introduced FLAGepitope was determined using PE-labeled antiCCR7 and FITC-labeled anti-FLAG M2 antibodies. Non-transfected, parental HEK293 cells were used as a control. One representative out of $n=2$ independent experiments is shown. (C) HEK293 cells transiently expressing either FLAG-ss-CCR7 or ss-FLAG-CCR7 were stained for surface CCR7 (24 h) in combination with either anti-FLAG M2 or anti-FLAG M1 antibodies. The anti-FLAG M1 antibody exclusively stains the FLAG-epitope if exposed at the free amino-terminus of a fusion protein. Dot plots of one representative flow cytometry experiment are shown $(n=3)$ consisting of 24 amino acids exclusively for CCR7 (UniProt ID: P47774) with a $P$ value of 0.961 and a cleavage site $P$ of 0.959 between residues Cys24 and GIn25, which are conserved between mouse and human CCR7. To experimentally confirm signal sequence cleavage and additionally to identify the precise cleavage site, we generated FLAGtagged mouse CCR7 constructs, where the FLAG-tag was either fused to the $\mathrm{N}$-terminal end of the predicted CCR7 precursor, termed FLAGss-CCR7, or directly after the predicted signal sequence and hence at the postulated immediate $\mathrm{N}$-terminus of the mature CCR7, referred as ss-FLAG-CCR7 (Fig. 2A). Analogous to the results obtained for human CCR7, also mouse CCR7 possessed a cleavable signal sequence as we were able to surface stain CCR7, but not the N-terminal FLAG-epitope using specific antibodies in cells expressing FLAG-ss-CCR7 (Fig. 2B). In contrast, the FLAG-epitope was nicely detectable on the surface of cells expressing ss-FLAG-CCR7 (Fig. 2B). Notably, a FLAG-tagged CCR7 construct has successfully been used previously ${ }^{36}$ in which an artificial prolactin leader sequence and a FLAG epitope were fused to an N-terminally truncated mouse CCR7 (starting with amino acid 26 of the full-length protein). We next exploited the anti-FLAG antibody M1 which exclusively detects the FLAG-epitope when it is located at the free amino-terminus of a fusion protein. Expression of ss-FLAGCCR7 and subsequent surface staining using the M1 antibody clearly revealed that the signal sequence of CCR7 consisting of the first 24 amino acids is cleaved off precisely after Cys 24 from the precursor protein (Fig. 2C).

\subsection{Mutations within the $h$ - and c-region of the signal sequence of CCR7 interferes with its surface expression}

Signal sequences do not share a particular sequence identity but show a characteristic tripartite structure starting with a highly variable n-region, a central hydrophobic h-region, and a short polar c-region. ${ }^{37}$ To further characterize the signal sequence of CCR7, we introduced mutations into the $\mathrm{h}$ - and c-region in $\mathrm{N}$-terminally peptide-tagged mouse CCR7 (Fig. 3A). We switched back to $\mathrm{N}$-terminally HA-tagged 
A
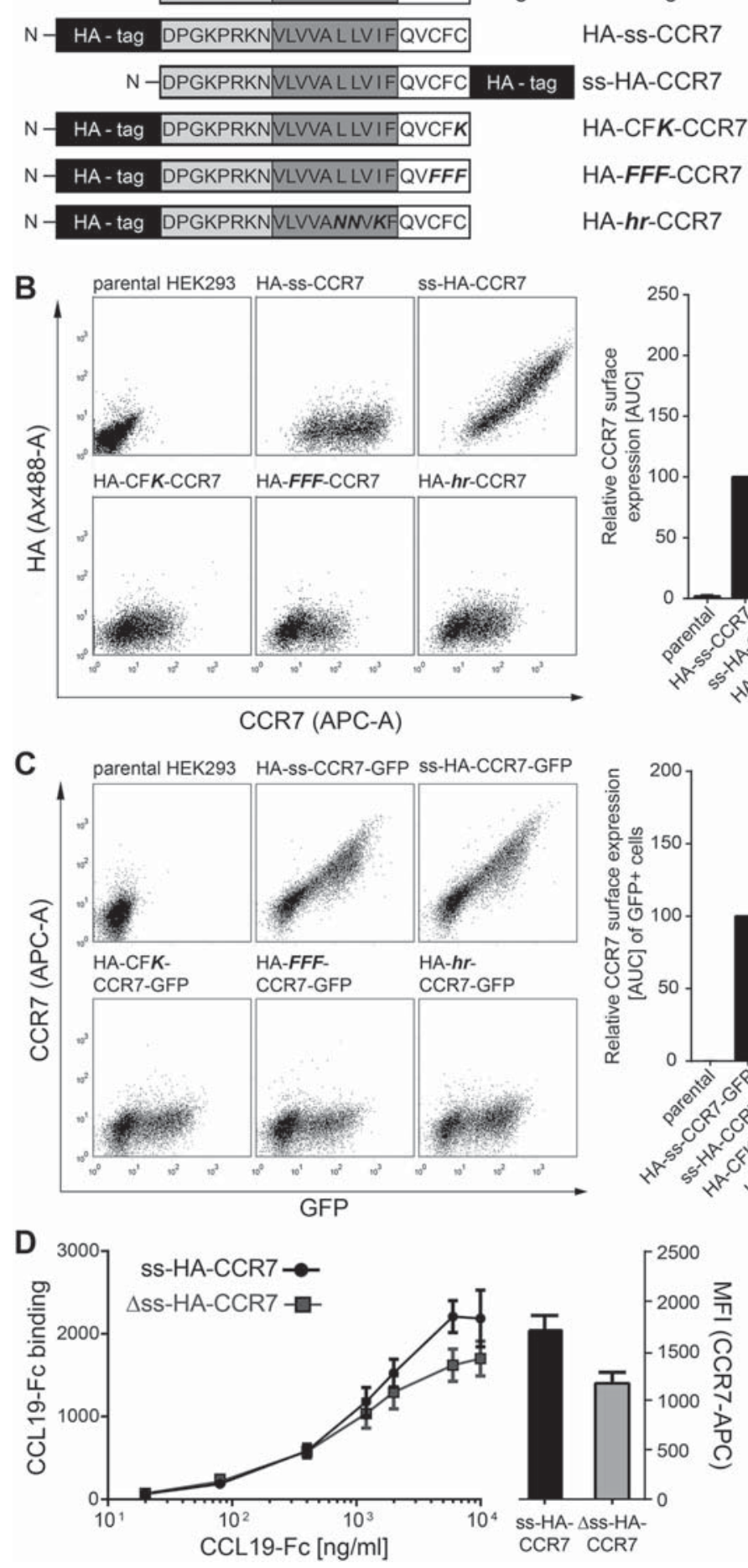
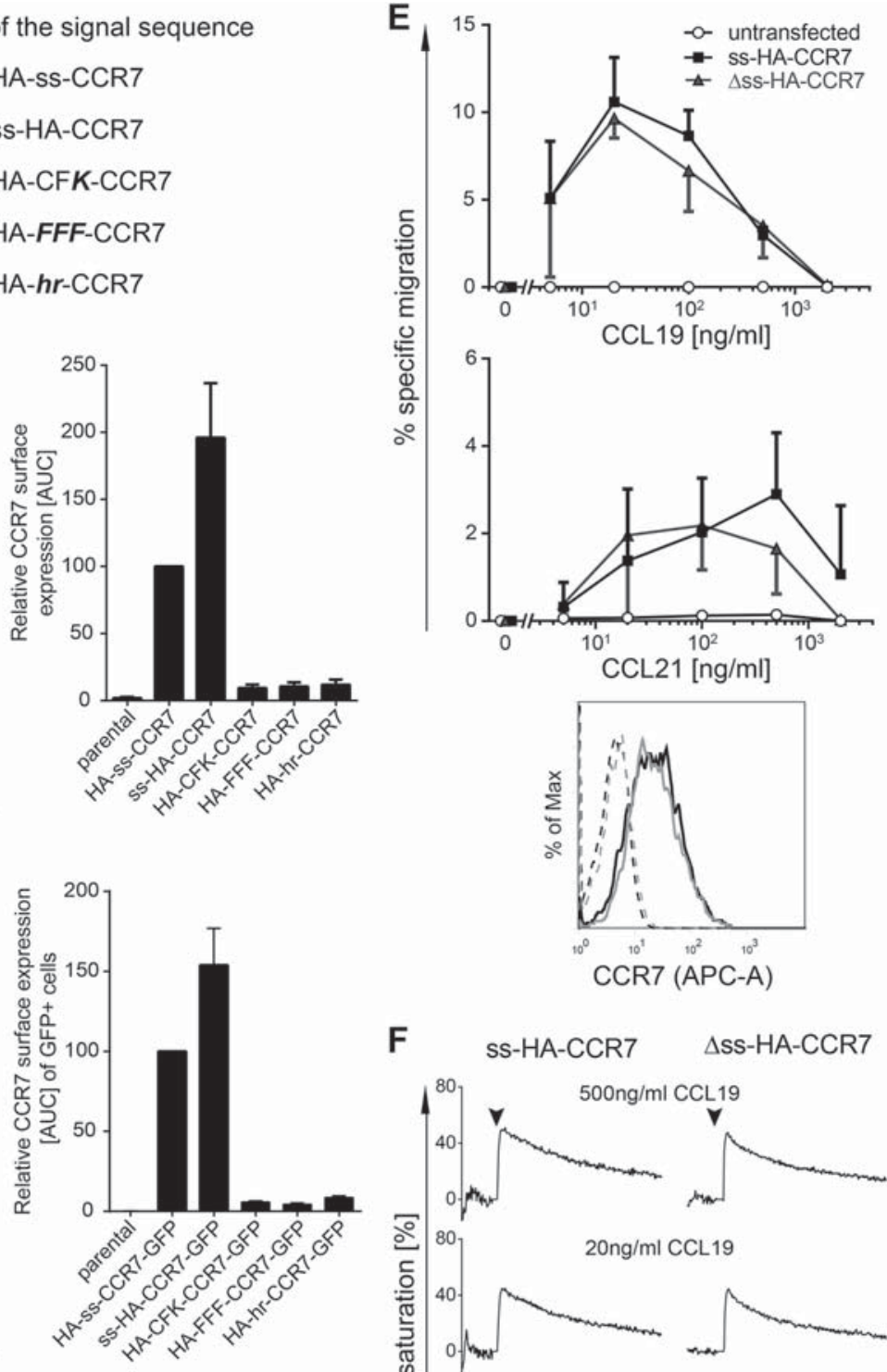

$\mathbf{F}$

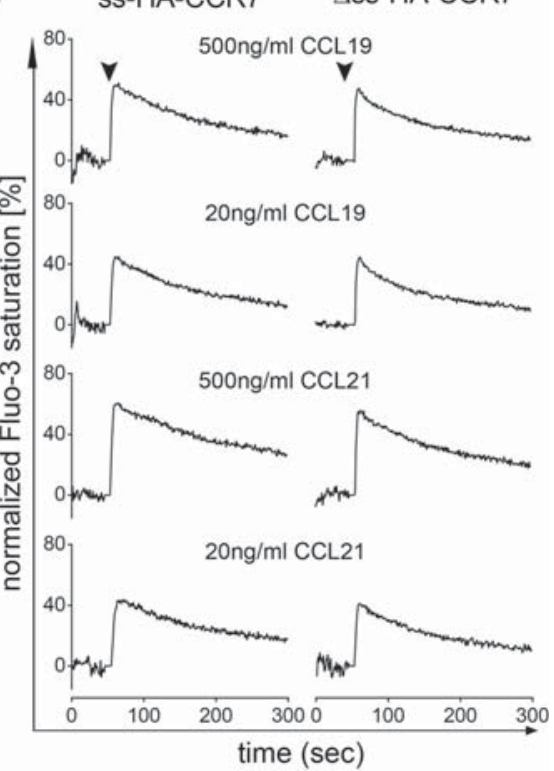

FIGURE 3 Point mutations in the h- and c-region of the signal sequence prevents CCR7 surface expression, whereas deletion of the entire signal sequence reveals functional expression. (A) Schematic representation of the signal sequence of mouse CCR7, including the variable nregion, the hydrophobic h-region and the polar c-region. Individually introduced mutations are indicated in bold and italics. (B) left panel: FACS analysis of HEK293 cells transiently transfected (46-48 h) with plasmids encoding for CCR7 variants illustrated in (A). Right panel: quantification of the relative CCR7 surface expression [AUC] derived from 3 separate experiments and determined by flow cytometry. The area under the curve $[A U C)$ ] was calculated by multiplying the mean APC fluorescence of live cells with the event count. AUC values from all receptor variants were normalized to those obtained from HA-ss-CCR7 transfectants included in the same experiment. (C) FACS analysis (left) and quantification (right, $n=3$ ) of relative surface expression of CCR7 variants fused C-terminally to GFP. (D) CCR7 lacking the entire signal sequence is readily expressed at the cell surface and normally binds CCL19. HEK293 cells stably expressing ss-HA-CCR7 or $\triangle$ ss-HA-CCR7, where the signal sequence is deleted, were incubated with graded concentrations of Fc-tagged CCL19. CCL19-FC binding (median \pm SD of PE fluorescence intensity derived from $n=4$ independent experiments) was determined in parallel to CCR7 surface expression (determined by an anti-CCR7 antibody). (E) 300-19 pre-B cells stably expressing similar amounts of ss-HA-CCR7 or $\Delta$ ss-HA-CCR7 (bottom panel) migrate similarly towards graded 
CCR7 to avoid potential perturbation caused by the negatively charged amino acids of the FLAG-epitope. We detected surface expression of CCR7 using an anti-CCR7 antibody in HEK293 cells expressing HA-ss-CCR7 and ss-HA-CCR7 (Fig. 3B). By contrast, the HA-epitope was only detectable at the surface of ss-HA-CCR7, but not of HA-ss-CCR7, transfected cells, suggesting that the signal sequence including the preceding HA-tag is cleaved off the mature protein (Fig. 3B), confirming our previous findings with FLAG-tagged CCR7. To further investigate the role of the cleavable signal sequence in regulating CCR7 expression, we designed in silico mutants within the $h$ - and c-region of the signal sequence of CCR7 that are predicted to become non-cleavable (Fig. 3A). The cleavage probability determined by SignalP 3.0 of the wild-type $\mathrm{N}$-terminus of CCR7 was $95.9 \%$. Exchanging 1 (Cys24; CFK-CCR7) or 3 (Cys22,Leu23,Cys24; FFF-CCR7) polar amino acids in the c-region or 3 hydrophobic amino acids (Leu15,Leu16,Ile18; $\mathrm{hr}$-CCR7) within the h-region of the signal sequence reduced the cleavage probability to $1.8 \%$ for CFK-CCR7, $0.7 \%$ for FFF-CCR7, and 0\% for hr-CCR7, respectively (Fig. 3A). Using site-directed mutagenesis, we subsequently cloned and expressed $\mathrm{N}$-terminally $\mathrm{HA}$-tagged versions of these CCR7 variants in HEK293 cells. All 3 signal sequence mutants of CCR7 were barely expressed at the cell surface as determined by flow cytometry using a CCR7-specific antibody (Fig. 3B), whereas HAss-CCR7 and ss-HA-CCR7 were readily detectable (Fig. 3B). Moreover, the N-terminal HA-tag was readily detectable at the surface of cells expressing ss-HA-CCR7, but not HA-CFK-CCR7, HA-FFF-CCR7, or HA-hr-CCR7 (Fig. 3B), suggesting that these mutants are not properly transported to the plasma membrane or are misfolded. To further examine their expression, we fused GFP to the C-terminus of these CCR7 variants. Although all transfected cells expressed GFP as a fusion protein, CCR7 was efficiently transported and expressed at the cell surface only in cells transfected with HA-ss-CCR7-GFP or ss-HA-CCR7-GFP (Fig. 3C). These data suggest that mutating the $\mathrm{h}$ - and c-region of the cleavable signal sequence prevents surface expression of CCR7, but does not result in a completely misfolded protein as the GFP fused to the C-terminus of the receptor variants was detectable through its fluorescence.

\subsection{The signal sequence of CCR7 is dispensable for functional surface expression}

Next, we aimed to determine whether the cleavable signal sequence is required for CCR7 surface expression. To this end, we deleted the first 24 amino acids of the CCR7 precursor. Expression of this $\triangle$ ss-HACCR7 in HEK293 cells was readily detected at the cell surface, but had a slightly reduced expression level in stable transfectants when compared to ss-HA-CCR7, which includes the signal sequence (Fig. 3D). To test their functionality, we first determined ligand binding to the receptor variants. ss-HA-CCR7 and $\triangle$ ss-HA-CCR7 displayed similar binding capacities for a recombinant Fc-tagged CCL1931 that correlated with their expression at the cell surface (Fig. 3D). Next, we stably expressed both constructs in the lymphocytic cell line 300-19 commonly used for functional characterization of chemokine receptors. ${ }^{28,38}$ Cell lines expressing similar levels of surface CCR7 were subjected to graded concentrations of CCL19 or CCL21 in Transwell migration assays. The efficiency and efficacy of chemokine-mediated cell migration did not substantially differ in cells expressing $\triangle$ ss-HA-CCR7 or ss-HA-CCR7 (Fig. 3E). In addition, stimulation of these two cell lines with CCL19 or CCL21 resulted in comparable transient elevations of intracellular $\mathrm{Ca}^{2+}$ concentrations (Fig. 3F). These data provide clear evidence that the cleavable signal sequence is dispensable for functional surface expression of CCR7. This is unexpected as the signal sequence of EBI1/CCR7 was originally proposed to facilitate efficient $\mathrm{N}$-tail translocation. ${ }^{26}$ The HA-epitope is fully accessible at the cell surface of transient transfectants expressing $\triangle \mathrm{ss}-\mathrm{HA}-\mathrm{CCR} 7-\mathrm{GFP}$, demonstrating that the $\mathrm{N}$-terminus is correctly translocated across the membrane (Fig. 4A).

\subsection{CCR7 with mutated signal sequence is retained in the ER}

Our data demonstrate that the signal sequence of CCR7 is dispensable for functional expression, whereas mutations aimed to prevent its cleavage hampered its surface expression (Figs. 3 and 4A). This prompted us to further investigate the intracellular localization of our CCR7 variants in stable transfected HEK293 cells by confocal microscopy. In line with our flow cytometric results, we found CCR7GFP to be predominantly expressed at the plasma membrane of cells expressing either HA-ss-CCR7-GFP, ss-HA-CCR7-GFP, or $\triangle$ ssHA-CCR7-GFP (Fig. 4B). We also detected CCR7-GFP in vesicular structures, presumably of the secretory pathway. In fact, intracellular CCR7-GFP partially co-localized with the ER marker Climp63 (Fig. 4B) and with TGN46. ${ }^{12}$ By contrast, HA-CFK-CCR7-GFP with a single codon mutation within the c-region of the cleavable signal sequence was barely detected at the plasma membrane (Fig. 4A and B) and predominantly expressed in intracellular compartments, where it colocalized with Climp63 (Fig. 4B). These findings provide evidence that interfering with cleavage of the signal sequence results in ER retention of CCR7.

concentrations of CCL19 or CCL21 in Transwell chemotaxis assays. Percent of specific cell migration towards CCR7 ligands is shown as mean \pm SD derived from $n=4$ (for 0, 100, and $500 \mathrm{ng} / \mathrm{ml} \mathrm{CCL19),} \mathrm{n}=3$ (for $20 \mathrm{ng} / \mathrm{ml} \mathrm{CCL19}$ and 0, 5, 20, 100, and $2000 \mathrm{ng} / \mathrm{ml} \mathrm{CCL21),} n=2$ (for $5 \mathrm{ng} / \mathrm{ml}$ CCL19 and $500 \mathrm{ng} / \mathrm{ml} \mathrm{CCL21),} \mathrm{and} n=1$ (for $2000 \mathrm{ng} / \mathrm{ml} \mathrm{CCL19).} \mathrm{Untransfected} \mathrm{300-19} \mathrm{cells} \mathrm{served} \mathrm{as} \mathrm{a} \mathrm{control.} \mathrm{CCR7} \mathrm{surface} \mathrm{expression} \mathrm{of} \mathrm{a}$ representative experiment is shown for ss-HA-CCR7 (black) or $\triangle$ ss-HA-CCR7 (grey) transfectants. Dashed lines: isotype controls. (F) $300-19$ pre$B$ cells as used in (E) were loaded with Fluo-3-AM, and changes in CCL19/CCL21-induced intracellular free calcium concentrations were analyzed over time by flow cytometry. Baseline was established for $45 \mathrm{~s}$ before chemokines (500 or $20 \mathrm{ng} / \mathrm{ml}$ ) were added, as indicated by arrowheads. Data were baseline-corrected and normalized to the maximal response induced by ionomycin. Data from one representative experiment out of three is shown 


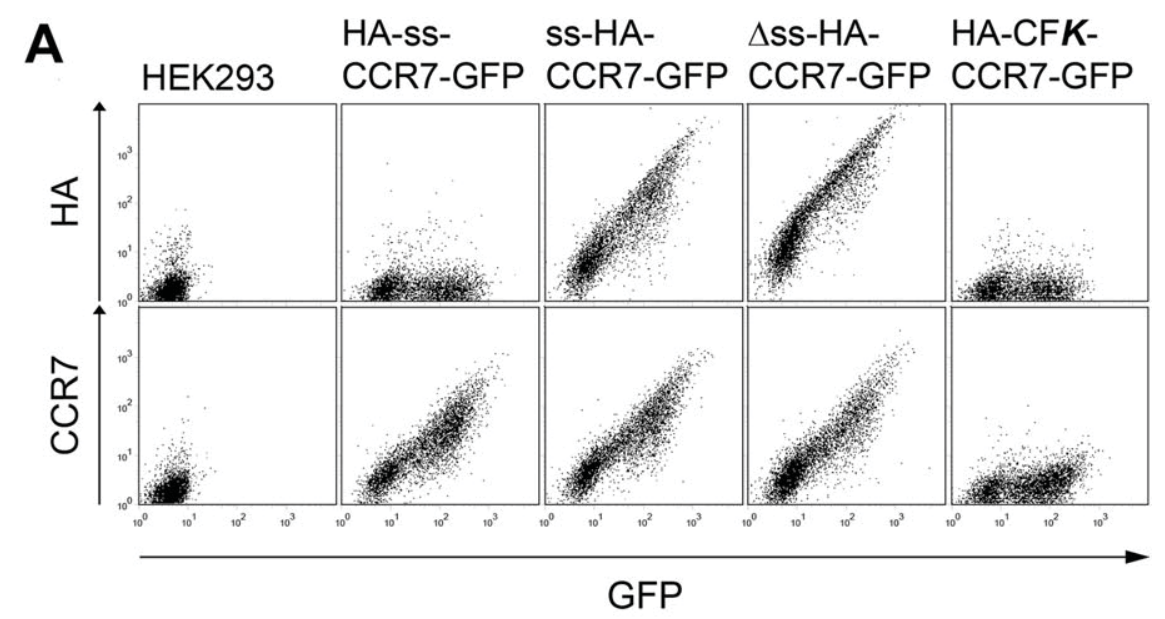

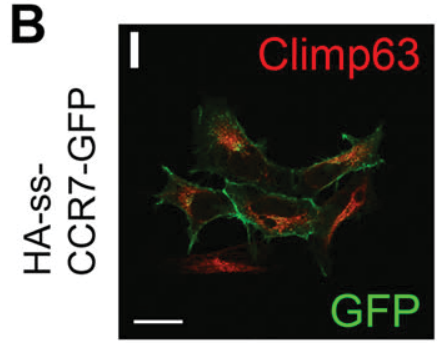
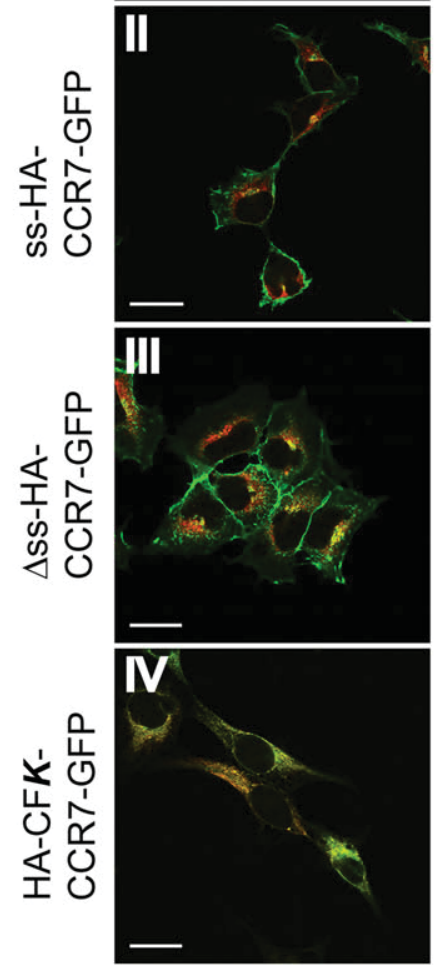
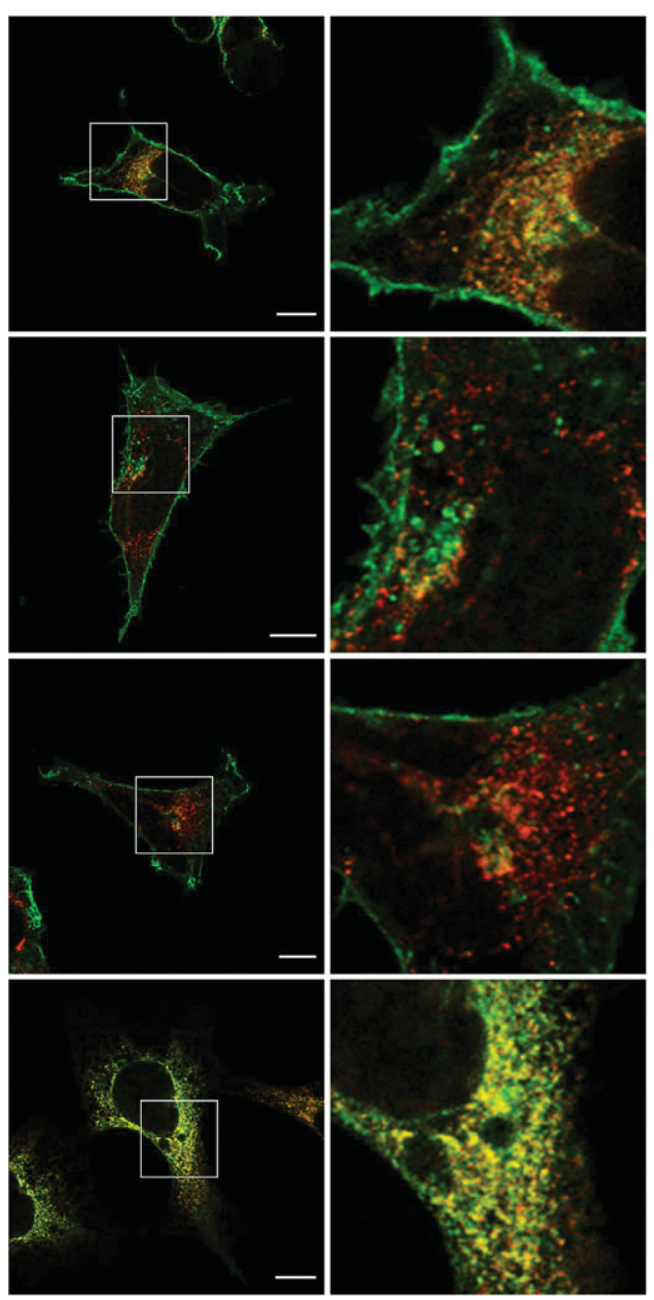

FIGURE 4 CCR7 with mutated signal sequence is retained in the ER. (A) HEK293 cells transiently expressing C-terminally GFPtagged CCR7 variants (48 h) were analyzed for surface and GFP expression by flow cytometry. One representative experiment out of 3 is shown. (B) Representative confocal microscopy images of cell clusters (left; scale bars: $25 \mu \mathrm{m}$ ) or single cells (right; scale bars: $10 \mu \mathrm{m}$, deconvoluted images) of HEK293 cell clones stably expressing GFP-tagged CCR7 variants (green) permeabilized and stained for the Climp63 (red). Zoomed images of the indicated regions are shown to the right

\subsection{The signal sequence of CCR7 promotes efficient ER to Golgi trafficking}

Although the signal sequence was not fundamental for functional expression, we suspected it to serve as regulatory element for efficient CCR7 surface expression. To address this in more details, we exploited the RUSH system ${ }^{39}$ to compare the spatial and temporal kinetics of trafficking of CCR7 possessing or not the signal sequence, independently from de novo gene transcription and protein synthesis. In the RUSH system, core streptavidin-fused hook proteins anchored to a specific intracellular donor compartment retain coexpressed streptavidin-binding peptide (SBP)-fused reporter proteins of interest due to the reversible interaction of SBP with core streptavidin. Upon the addition of biotin, reporters are synchronously released from the hook. In confocal images of the ER-hooked CCR7 reporters, both ss-CCR7-RUSH-GFP and $\triangle$ ss-CCR7-RUSH-GFP localized in reticular structures characteristic for the ER, but did not colocalize with the cis-Golgi marker GM130 (Fig. 5A). Adding biotin released ss-CCR7-RUSH-GFP from the ER and allowed its trafficking to the Golgi, where it readily colocalized with GM130 after $10 \mathrm{~min}$ 
A

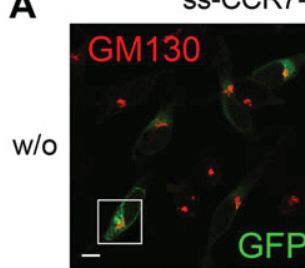

10
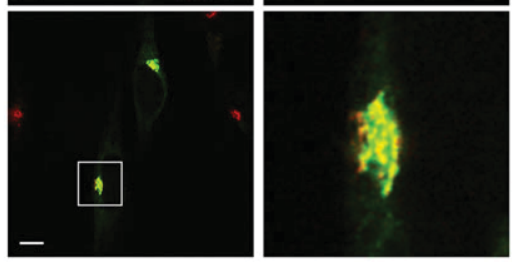

B $\boldsymbol{D}$ ss-CCR7-RUSH-GFP 口 $\triangle$ SS-CCR7-RUSH-GFP

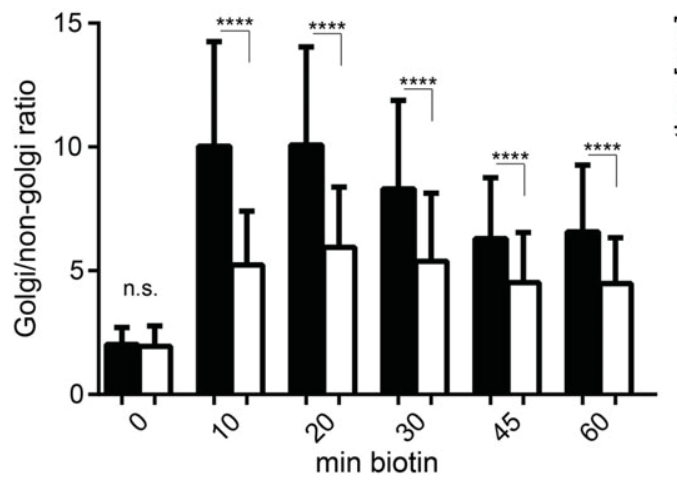

$\Delta$ ss-CCR7-RUSH-GFP
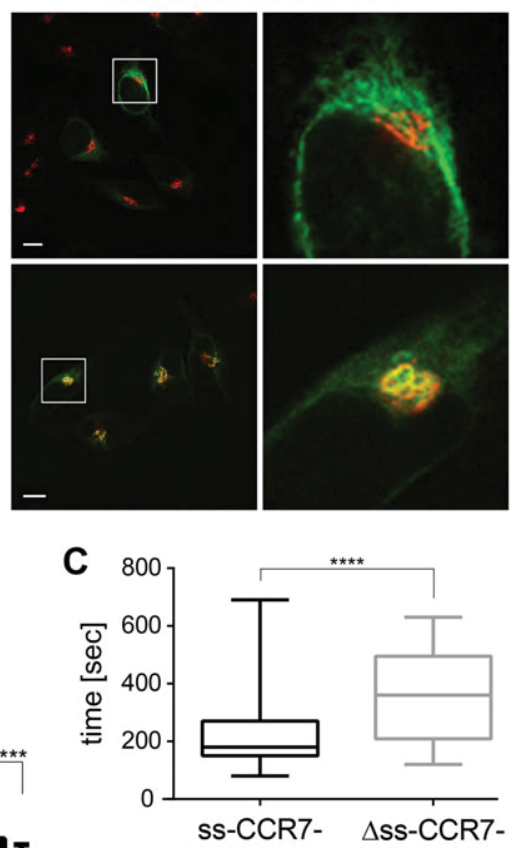

RUSH-GFP RUSH-GFP

FIGURE 5 Reduced ER to Golgi transport of CCR7 lacking the $\mathrm{N}$-terminal signal sequence. (A) Representative overview images of GM130 immunostaining (cis-Golgi marker, red) in HeLa cells transiently expressing ss-CCR7-RUSH-GFP or $\Delta$ ss-CCR7-RUSH-GFP (green) before (w/o, upper panel) and 10 min after biotin-mediated release of the receptor from the ER-hook are shown; $10 \mu \mathrm{m}$ scale bars. Enlarged images of the boxed regions are shown aside. (B) Quantification and statistical analysis of fluorescence intensity of ss-CCR7RUSH-GFP (black bars) or $\Delta$ ss-CCR7-RUSH-GFP (white bars) at the cis-Golgi area determined in (A). Mean values $\pm S D$ (n.s., not statistically significant; ${ }^{* * * *} P<0.0001$ ) including data sets for $n=120$ individual cells per condition collected from $n=3$ separate experiments and analyzed by a two-tailed Mann-Whitney $U$ test. No particular Golgi association of CCR7 is defined by a Golgi/non-Golgi ratio of 1.0. (C) Box and Whiskers plot ${ }^{* * * *} P<0.0001$, two-tailed Mann-Whitney $U$ test) showing the kinetics of receptor targeting to the Golgi area upon synchronized release of the receptor from the ER as assessed by lifecell imaging using the median (line in the middle of the box) and the extreme values (whiskers) of seconds passed until first occurrence of green fluorescence derived from ss-CCR7-RUSH-GFP or $\Delta$ ssCCR7-RUSH-GFP in the medial-Golgi area (defined by mOrange2-Golgi-7). The box extends from the 25 th to 75 th percentiles

(Fig. 5A). Interestingly, a significantly lower pool of ER-released $\Delta$ ssCCR7-RUSH-GFP reached the Golgi after $10 \mathrm{~min}$ of biotin treatment and remained ER associated to a considerable extent (Fig. 5A and B). Quantification of coincidence, calculated as ratio of receptor present in the Golgi area from cells with similar mean GFP expression levels and containing definable Golgi structures, revealed significantly higher Golgi association of ss-CCR7-RUSH-GFP compared to $\Delta$ ss-CCR7-RUSH-GFP (Fig. 5B). A maximum of 1.9-fold higher Golgi association for ss-CCR7-RUSH-GFP was found $10 \mathrm{~min}$ after biotin addition, decreasing to a constant value of approximately 1.5 -fold higher Golgi association after 30 or 60 min of trafficking (Fig. 5B). Confocal live-cell imaging in HeLa coexpressing the orange fluorescent trans-Golgi marker Golgi-7 together with either ss-CCR7-RUSHGFP or $\Delta$ ss-CCR7-RUSH-GFP revealed a significantly faster onset for ss-CCR7-RUSH-GFP (median: $180 \mathrm{~s}$ ) with the Golgi than for $\Delta$ ssCCR7-RUSH-GFP (median: $360 \mathrm{~s}$ ) (Fig. 5C). Altogether, these observations suggest a weak, but significant ER-to-Golgi trafficking defect of $\Delta$ ss-CCR7-RUSH-GFP.

\subsection{The signal sequence promotes efficient recruitment of CCR7 to ER exit sites}

Since $\Delta$ ss-CCR7-RUSH-GFP was delayed in ER-to-Golgi trafficking and showed no tendency to "catch up" with the ss-CCR7-RUSH-GFP over $1 \mathrm{~h}$ of trafficking (Fig. 5B), we wondered whether this differential behavior of the mutant receptor lacking the signal sequence emerges already at an early step close to ER exit. Secretory protein transport from the ER to the Golgi is mediated by COPII-vesicles ${ }^{40}$ known to participate in regulating GPCR export trafficking. ${ }^{41}$ COPII vesicles form exclusively on specialized regions of the ER called ERES. We hypothesized that the trafficking defect of $\triangle$ ss-CCR7 might be due to a defect in sorting to ERES. To test the hypothesis, we expressed ss-CCR7RUSH-GFP or $\triangle$ ss-CCR7-RUSH-GFP in HeLa cells and determined the kinetics of export at $15^{\circ} \mathrm{C}$. Culturing cells at this low temperature allows secretory cargo to be incorporated into ERES and ERGIC, but does block further trafficking. ${ }^{42}$ Thus, this assay measures the kinetics of recruitment of CCR7 into ERES. Confocal imaging demonstrated a clear coincidence of green fluorescence derived from ss-CCR7-RUSHGFP with the ERES marker Sec31A after 1 and $2 \mathrm{~h}$ of biotin addition (Fig. 6A), which was significantly lower for $\triangle$ ss-CCR7-RUSH-GFP (Fig. 6B). This indicates a defect of sorting $\triangle$ ss-CCR7 into ERES, which is in accordance with the finding that this mutant exhibits defects in trafficking.

Altogether, we demonstrate that CCR7 possesses a unique $\mathrm{N}$ terminal signal sequence comprising 24 amino acids which appears to promote maturation of the GPCR and sorting into ERES for efficient cargo delivery to the plasma membrane.

\section{4 | DISCUSSION}

Chemokine receptors sense chemokine gradients to guide cell migration in space and time in a highly organized and tightly regulated manner. Thereby, a controlled and timely expression of the receptor 
A
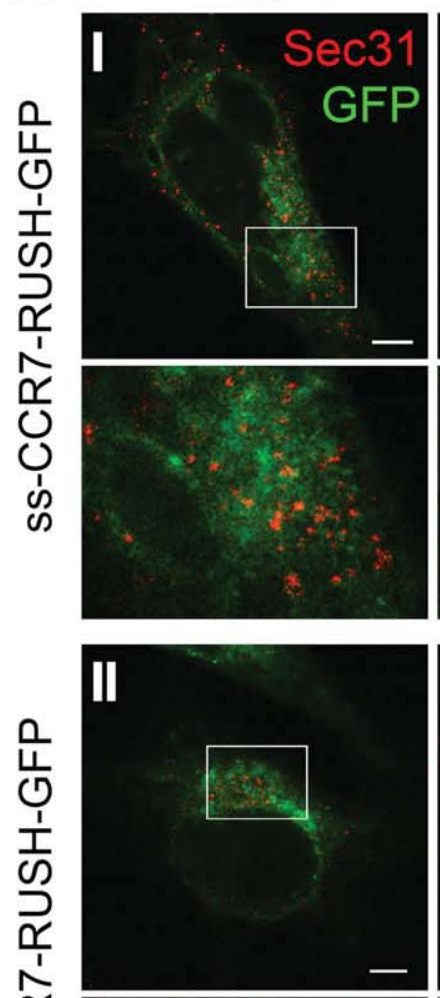

ㅁ․
0
$\grave{d}$
0
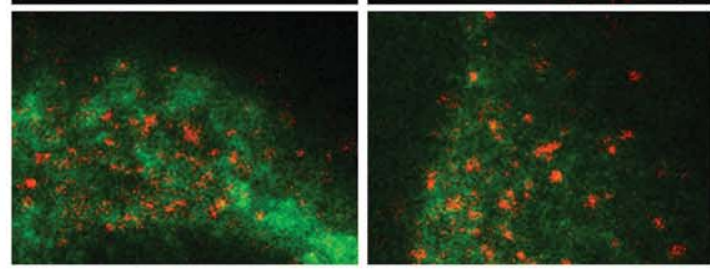

B

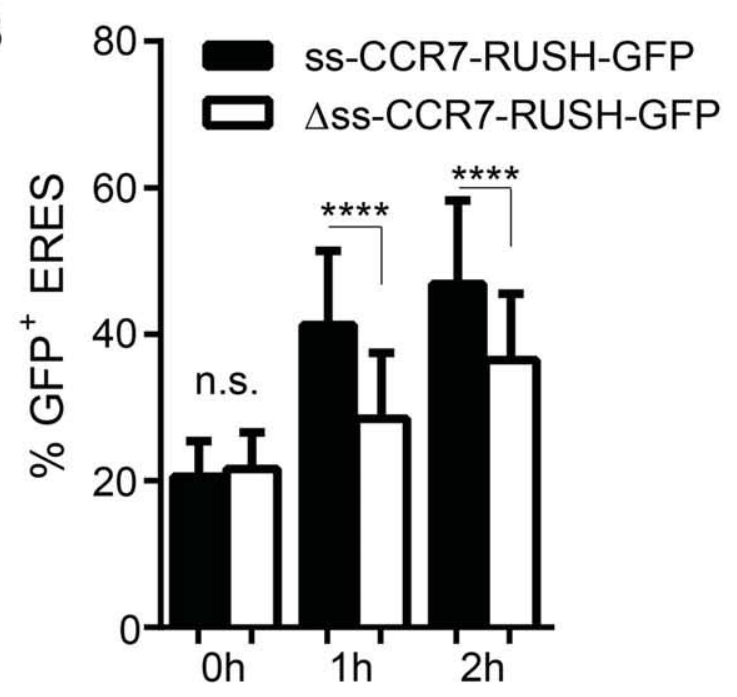

is critical for chemokine recognition. The initial interaction between a chemokine and its cognate receptor occurs in 2 major steps that seem to be consistent among all chemokine receptors, whereas several additional intermediate interactions have been described for specific chemokines. Overall, the $\mathrm{N}$-terminus of the receptor is essential for the first step of chemokine binding. ${ }^{3,4}$ Consistent with this paradigm, an $\mathrm{N}$-terminal peptide of CCR7 was found to bind to the $\mathrm{N}$-loop and

\section{$2 \mathrm{~h}$}
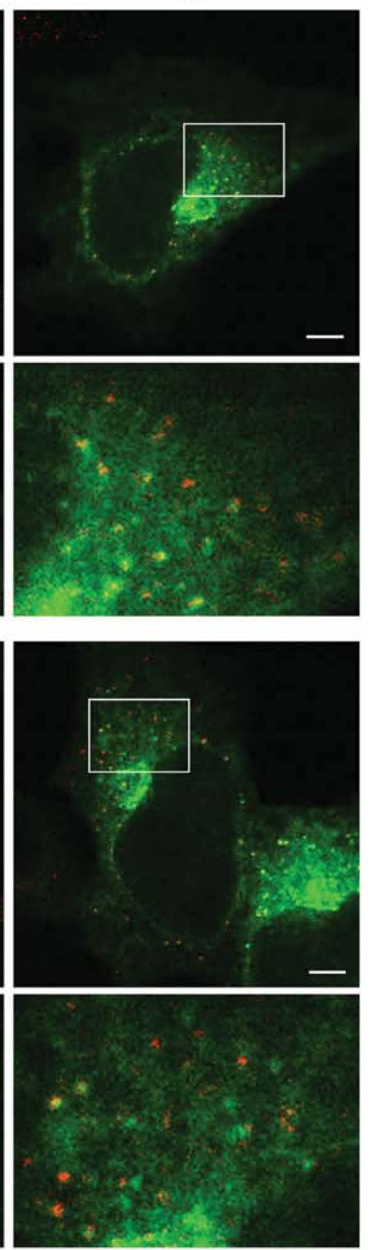

FIGURE 6 Efficient recruitment of CCR7 cargo to ERES is facilitated by the $\mathrm{N}$-terminal signal sequence. (A) Confocal fluorescent images of HeLa cells transiently expressing ss-CCR7-RUSH-GFP or $\Delta$ ss-CCR7-RUSH-GFP at 0,1 , or $2 \mathrm{~h}$ after synchronous release of the green fluorescent reporter from the ER-hook. ERESs of fixed cells were immunostained for Sec31A (red). Scale bars: $5 \mu \mathrm{m}$. Magnifications of the boxed regions are shown underneath. (B) Quantification and statistical analysis of the data sets defined in (A). Bar graph displaying the percentages of ERESs per cell (dots with Sec31A - Alexa Fluor 568 fluorescence) containing green CCR7-RUSH-GFP (black bars; $40 \leq n \leq 63$; $n$, number of cells transfected with ss-CCR7-RUSH-GFP plotted per time-point after addition of biotin; white bars; $40 \leq n \leq 47$; $n$, number of cells transfected with $\Delta$ ss-CCR7-RUSH-GFP plotted per time-point after addition of biotin). Mean values \pm SD (n.s., not statistically significant; ${ }^{* * * *} P<0.0001$ ) derived from $n=3$ independent experiments were analyzed by a two-tailed Mann-Whitney U test the third $\beta$-strand of CCL21,43 whereas binding to CCL19 was not addressed in that study.

Here, we identify a unique cleavable $\mathrm{N}$-terminal signal sequence for CCR7. All other chemokine receptors, as most other GPCRs, lack such a cleavable N-terminal signal sequence and use a signal anchor sequence in TM1 for membrane insertion and subsequent export for surface expression. Only a minority of GPCRs possesses 
cleavable $\mathrm{N}$-terminal signal sequences, which fulfill distinct critical functions. ${ }^{18,19}$ For instance, the cleavable signal sequence of the class A GPCR protease-activated receptor 1 is required for its expression. ${ }^{44}$ The signal sequence of the endothelin $B$ receptor $E T_{B} R$, another class $A$ of GPCRs, was shown to be necessary for the translocation of the receptor's $\mathrm{N}$-terminal tail across the ER membrane. ${ }^{45}$ Furthermore, cleavage of the signal sequence was found to be obligatory for the processing and trafficking to the cell surface of the class B GPCR glucagon-like peptide-1. ${ }^{46}$ Our study reveals that the signal sequence of CCR7 is not essential for biosynthesis, membrane insertion, and transport of this receptor to the plasma membrane. However, using the signal sequence deletion mutant $\triangle$ ss-CCR7, we demonstrated that the signal sequence controlled a fast recruitment of CCR7 into ERESs, facilitating efficient CCR7-containing COPII-vesicle trafficking from the ER to the Golgi. As the $\Delta$ ss-CCR7 mutant was still able to reach the plasma membrane, TM1 is likely to serve as a functional internal signal anchor sequence. ${ }^{47,48}$ This notion is supported by our finding that an $\mathrm{N}$-terminal epitope tag fused to $\triangle \mathrm{ss}$-CCR7 was readily detectable at the cell surface pointing to an efficient posttranslational translocation of the remaining 35 residues short $\mathrm{N}$-tail of the receptor across the membrane. Here, we report that the signal sequence of CCR7 is dispensable for its insertion into the ER membrane, but appears to promote maturation of the receptor and sorting into ERES for efficient receptor trafficking, a function which, to the best of our knowledge, has not been reported for any other GPCR yet.

A wide range of post-targeting functions of signal sequences have been described, ${ }^{49}$ such as interaction with the translocon ${ }^{50}$ or regulation of the ribosome-translocon junction. ${ }^{51}$ Interestingly, the sequence following the signal sequence of $E T_{B} R$ is known to be required for efficient translocon gating at the ER membrane. ${ }^{52}$

We identified critical residues within the $\mathrm{h}$ - and c-region of the signal sequence of CCR7. Mutating these residues impaired CCR7 trafficking to the plasma membrane due to retention in the ER, where the signal sequence is most probably not removed from the fully synthesized protein. A potential post-targeting effect of a native signal sequence to promote the gating of the protein-conducting translocon of the ER membrane, as described for the rat corticotropin-releasing factor receptor 1,53 might be absent in the CCR7 mutants, thereby preventing their proper insertion into the ER lumen and/or processing of the newly synthesized protein. Alternatively, these mutations might destabilize secondary structures leading to association of unfolded receptor intermediates with the membrane-cytosol interface resulting in their retention in the ER or prolonging the interaction with ER chaperones. The exit rate of native proteins from the ER is considered as most critical step for efficient secretion in terms of speed and yield. The CCR7 mutant lacking the signal sequence showed a mild, but significant sorting defect, resulting in a subsequent retarded release from the ER as evidenced from RUSH experiments.

Besides affecting targeting efficiency, signal sequences can influence the timing of cleavage from secreted glycoproteins by signal peptidase, which is thought to control $\mathrm{N}$-glycosylation ${ }^{54}$ and provides a high-affinity ligand for the translocon-associated membrane chaperone calnexin. As CCR7 is known to be glycosylated, ${ }^{15}$ it is tempting to speculate that membrane bound calnexin might assist the correct folding and maturation process of CCR7 to prevent export of premature cargo and to achieve an export-competent protein ready to be recruited into ER-derived COPII transport vesicles. ${ }^{55,56}$ In fact, correct glycosylation and polysialylation of CCR7 controls chemokine recognition and discrete signal transduction. ${ }^{14,15}$

Finally, we would like to point out that the identification of a cleavable signal sequence of CCR7 is critical for the design of peptides to generate antibodies for detection. Synthetic peptides covering the $\mathrm{N}$ termini of chemokine receptors in general have regularly been used for immunization and raising antibodies. Available antibodies might, therefore, be re-evaluated to ensure that they detect the mature form of CCR7 and not a non-cleaved precursor. Moreover, our finding also needs to be considered for the design and development of validated new antibodies against CCR7 for numerous applications and for a successful epitope-tagging of the receptor.

\section{AUTHORSHIP}

E.UvA. and D.F.L. designed the study, analyzed data, and wrote the manuscript. E.UvA. and A.V.R. performed all experiments. H.F. contributed vital reagents and intellectual input. D.F.L. supervised the overall study.

\section{ACKNOWLEDGMENTS}

This study was supported in parts by research funding from the Swiss National Science Foundation (grant 31003A_169936), the Thurgauische Stiftung für Wissenschaft und Forschung, and the Swiss State Secretariat for Education, Research and Innovation to D.F.L.

We thank Dr. Jens Stein for providing the pcDNA3.1-ss-FLAGCCR7 plasmid, Dr. Eva-Maria Boneberg, Dr. Margit Klier-Richter, and Nicole Kammerer for preliminary work on human chemokine receptors and FLAG-tagged murine CCR7 constructs.

\section{DISCLOSURE}

The authors declare no financial conflict of interest.

\section{REFERENCES}

1. Griffith JW, Sokol CL, Luster AD. Chemokines and chemokine receptors: positioning cells for host defense and immunity. Annu Rev Immunol. 2014;32:659-702.

2. Bachelerie F, Ben-Baruch A, Burkhardt AM, et al. International Union of Pharmacology. LXXXIX. Update on the extended family of chemokine receptors and introducing a new nomenclature for Atypical chemokine receptors. Pharmacol Rev. 2014;66:1-79.

3. Thiele S, Rosenkilde MM. Interaction of chemokines with their receptors-from initial chemokine binding to receptor activating steps. Curr Med Chem. 2014;21:3594-3614.

4. Kufareva I, Gustavsson M, Zheng Y, Stephens BS, Handel TM, What do structures tell us about chemokine receptor function and antagonism? Annu Rev Biophys. 2017;46:175-198.

5. Crump MP, Gong JH, Loetscher P, et al. Solution structure and basis for functional activity of stromal cell-derived factor-1; dissociation of CXCR4 activation from binding and inhibition of HIV-1. EMBO J. 1997;16:6996-7007. 
6. Legler DF, Thelen M. New insights in chemokine signaling. F1000Res. 2018;7:95.

7. Forster R, Davalos-Misslitz AC, Rot A. CCR7 and its ligands: balancing immunity and tolerance. Nat Rev Immunol. 2008;8:362-371.

8. Hauser MA, Legler DF. Common and biased signaling pathways of the chemokine receptor CCR7 elicited by its ligands CCL19 and CCL21 in leukocytes. J Leukoc Biol. 2016;99:869-882.

9. Legler DF, Uetz-von Allmen E, Hauser MA. CCR7: roles in cancer cell dissemination, migration and metastasis formation. Int J Biochem Cell Biol. 2014;54C:78-82.

10. Legler DF, Krause P, Scandella E, Singer E, Groettrup M. Prostaglandin E2 is generally required for human dendritic cell migration and exerts its effect via EP2 and EP4 receptors. J Immunol. 2006;176: 966-973.

11. Hauser MA, Schaeuble K, Kindinger I, et al. Inflammation-induced CCR7 oligomers form scaffolds to integrate distinct signaling pathways for efficient cell migration. Immunity. 2016;44: 59-72.

12. Schaeuble K, Hauser MA, Rippl AV, et al. Ubiquitylation of the chemokine receptor CCR7 enables efficient receptor recycling and cell migration. J Cell Sci. 2012;125:4463-4474.

13. Phillips AJ, Taleski D, Koplinski CA, et al. CCR7 Sulfotyrosine enhances CCL21 binding. Int J Mol Sci. 2017;18:E1857.

14. Kiermaier E, Moussion C, Veldkamp CT, et al. Polysialylation controls dendritic cell trafficking by regulating chemokine recognition. Science. 2016;351:186-190.

15. Hauser MA, Kindinger I, Laufer JM, et al. Distinct CCR7 glycosylation pattern shapes receptor signaling and endocytosis to modulate chemotactic responses. J Leukoc Biol. 2016;99:993-1007.

16. Drake MT, Shenoy SK, Lefkowitz RJ. Trafficking of G protein-coupled receptors. Circ Res. 2006;99:570-582.

17. Bennett LD, Fox JM, Signoret N. Mechanisms regulating chemokine receptor activity. Immunology. 2011;134:246-256.

18. Nanoff C, Freissmuth M. ER-bound steps in the biosynthesis of G protein-coupled receptors. Subcell Biochem. 2012;63:1-21.

19. Schulein R, Westendorf C, Krause G, Rosenthal W. Functional significance of cleavable signal peptides of $\mathrm{G}$ protein-coupled receptors. Eur J Cell Biol. 2012;91:294-299.

20. Hebert DN, Molinari M. In and out of the ER: protein folding, quality control, degradation, and related human diseases. Physiol Rev. 2007;87:1377-1408

21. Poms M, Ansorge P, Martinez-Gil L, et al. NMR investigation of structures of G-protein coupled receptor folding intermediates. J Biol Chem. 2016;291:27170-27186.

22. Ogilvie P, Thelen S, Moepps B, et al. Unusual chemokine receptor antagonism involving a mitogen-activated protein kinase pathway. J Immunol. 2004;172:6715-6722.

23. Favre N, Camps M, Arod C, Chabert C, Rommel C, Pasquali C. Chemokine receptor CCR2 undergoes transportin1-dependent nuclear translocation. Proteomics. 2008;8:4560-4576.

24. Orsini MJ, Parent JL, Mundell SJ, Benovic JL, Marchese A. Trafficking of the HIV coreceptor CXCR4. Role of arrestins and identification of residues in the c-terminal tail that mediate receptor internalization. $J$ Biol Chem. 1999;274:31076-31086.

25. Marchese A, Benovic JL. Agonist-promoted ubiquitination of the $G$ protein-coupled receptor CXCR4 mediates lysosomal sorting. J Biol Chem. 2001;276:45509-45512.

26. Wallin $\mathrm{E}$, von Heijne $\mathrm{G}$. Properties of $\mathrm{N}$-terminal tails in $\mathrm{G}$-protein coupled receptors: a statistical study. Protein Eng. 1995;8:693-698.
27. Yoshida R, Imai T, Hieshima K, et al. Molecular cloning of a novel human CC chemokine EBI1-ligand chemokine that is a specific functional ligand for EBI1, CCR7. J Biol Chem. 1997;272:13803-13809.

28. Willimann K, Legler DF, Loetscher $M$, et al. The chemokine SLC is expressed in T cell areas of lymph nodes and mucosal lymphoid tissues and attracts activated T cells via CCR7. Eur J Immunol. 1998;28: 2025-2034.

29. Bendtsen JD, Nielsen H, von Heijne G, Brunak S. Improved prediction of signal peptides: signalP 3.0. J Mol Biol. 2004;340:783-795.

30. Marchese A, Raiborg C, Santini F, Keen JH, Stenmark H, Benovic JL. The E3 ubiquitin ligase AIP4 mediates ubiquitination and sorting of the G protein-coupled receptor CXCR4. Dev Cell. 2003;5:709-722.

31. Otero C, Groettrup M, Legler DF. Opposite Fate of Endocytosed CCR7 and Its ligands: recycling versus degradation. J Immunol. 2006;177:2314-2323

32. Li C, Wen A, Shen B, Lu J, Huang Y, Chang Y. FastCloning: a highly simplified, purification-free, sequence- and ligation-independent PCR cloning method. BMC Biotechnol. 2011;11:92

33. Shaner NC, Lin MZ, McKeown MR, et al. Improving the photostability of bright monomeric orange and red fluorescent proteins. Nat Methods. 2008;5:545-551.

34. Cromey DW. Avoiding twisted pixels: ethical guidelines for the appropriate use and manipulation of scientific digital images. Sci Eng Ethics. 2010;16:639-667

35. Emanuelsson O, Brunak S, von Heijne G, Nielsen H. Locating proteins in the cell using TargetP, SignalP and related tools. Nat Protoc. 2007;2:953-971.

36. Ngo VN, Tang HL, Cyster JG. Epstein-Barr virus-induced molecule 1 ligand chemokine is expressed by dendritic cells in lymphoid tissues and strongly attracts naive T cells and activated B cells. J Exp Med. 1998;188:181-191.

37. Martoglio B. Intramembrane proteolysis and post-targeting functions of signal peptides. Biochem Soc Trans. 2003;31:1243-1247.

38. Otero C, Eisele PS, Schaeuble K, Groettrup M, Legler DF. Distinct motifs in the chemokine receptor CCR7 regulate signal transduction, receptor trafficking and chemotaxis. J Cell Sci. 2008;121:2759-2767.

39. Boncompain G, Divoux S, Gareil N, et al. Synchronization of secretory protein traffic in populations of cells. Nat Methods. 2012;9:493-498.

40. Barlowe C, Orci L, Yeung T, et al. COPII: a membrane coat formed by Sec proteins that drive vesicle budding from the endoplasmic reticulum. Cell. 1994;77:895-907.

41. Dong C, Filipeanu CM, Duvernay MT, Wu G. Regulation of G protein-coupled receptor export trafficking. Biochim Biophys Acta. 2007;1768:853-870.

42. Farhan H, Weiss M, Tani K, Kaufman RJ, Hauri HP. Adaptation of endoplasmic reticulum exit sites to acute and chronic increases in cargo load. EMBO J. 2008;27:2043-2054.

43. Love M, Sandberg JL, Ziarek JJ, et al. Solution structure of CCL21 and identification of a putative CCR7 binding site. Biochemistry. 2012;51:733-735

44. Zampatis DE, Rutz C, Furkert J, et al. The protease-activated receptor 1 possesses a functional and cleavable signal peptide which is necessary for receptor expression. FEBS Lett. 2012;586:2351-2359.

45. Kochl R, Alken M, Rutz C, et al. The signal peptide of the G proteincoupled human endothelin $B$ receptor is necessary for translocation of the $\mathrm{N}$-terminal tail across the endoplasmic reticulum membrane. J Biol Chem. 2002;277:16131-16138.

46. Huang Y, Wilkinson GF, Willars GB. Role of the signal peptide in the synthesis and processing of the glucagon-like peptide-1 receptor. $\mathrm{Br} J$ Pharmacol. 2010;159:237-251. 
47. Haeuptle MT, Flint N, Gough NM, Dobberstein B. A tripartite structure of the signals that determine protein insertion into the endoplasmic reticulum membrane. J Cell Biol. 1989;108:1227-1236.

48. Higy M, Junne T, Spiess M. Topogenesis of membrane proteins at the endoplasmic reticulum. Biochemistry. 2004;43:12716-12722.

49. Kilic A, Klose S, Dobberstein B, Knust E, Kapp K. The Drosophila Crumbs signal peptide is unusually long and is a substrate for signal peptide peptidase. Eur J Cell Biol. 2010;89:449-461.

50. Kim SJ, Mitra D, Salerno JR, Hegde RS. Signal sequences control gating of the protein translocation channel in a substrate-specific manner. Dev Cell. 2002;2:207-217.

51. Rutkowski DT, Lingappa VR, Hegde RS. Substrate-specific regulation of the ribosome-translocon junction by $\mathrm{N}$-terminal signal sequences. Proc Natl Acad Sci USA. 2001;98:7823-7828.

52. Alken $M$, Schmidt A, Rutz $C$, et al. The sequence after the signal peptide of the $\mathrm{G}$ protein-coupled endothelin $\mathrm{B}$ receptor is required for efficient translocon gating at the endoplasmic reticulum membrane. Mol Pharmacol. 2009;75:801-811.

53. Alken $M$, Rutz $C$, Kochl $R$, et al. The signal peptide of the rat corticotropin-releasing factor receptor 1 promotes receptor expression but is not essential for establishing a functional receptor. Biochem J. 2005;390:455-464.

54. Rutkowski DT, Ott CM, Polansky JR, Lingappa VR. Signal sequences initiate the pathway of maturation in the endoplasmic reticulum lumen. $J$ Biol Chem. 2003;278:30365-30372.

55. Mancias JD, Goldberg J. Exiting the endoplasmic reticulum. Traffic. 2005;6:278-285.

56. Mizrachi D, Segaloff DL. Intracellularly located misfolded glycoprotein hormone receptors associate with different chaperone proteins than their cognate wild-type receptors. Mol Endocrinol. 2004;18: 1768-1777. 